\title{
Associations between the degree of early lactation inflammation and performance, metabolism, and immune function in dairy cows
}

\author{
M. M. McCarthy, ${ }^{*}$ T. Yasui, ${ }^{*}$ M. J. B. Felippe, $\dagger$ and T. R. Overton*1 \\ *Department of Animal Science, and \\ †Department of Clinical Sciences, College of Veterinary Medicine, Cornell University, Ithaca, NY 14853
}

\begin{abstract}
The objective of the current study was to determine associations between the severity of systemic inflammation during the early postpartum period and performance, energy metabolism, and immune function in dairy cows. Cows were assigned to categorical quartiles $(\mathrm{Q} ; \mathrm{Q} 1=0.18-0.59, \mathrm{Q} 2=0.60-1.14, \mathrm{Q} 3=1.15-2.05$, and $\mathrm{Q} 4=2.06-2.50 \mathrm{~g}$ of haptoglobin/L) based on the highest plasma haptoglobin (Hp) concentration measured during wk 1 postpartum. Although cows were assigned to different categories of inflammation during the postpartum period, we detected a quadratic relationship of inflammation on prepartum dry matter intake (DMI) and body weight (BW) such that cows in Q2 had lower prepartum DMI and cows in Q2 and Q3 had lower prepartum BW compared with cows in the other quartiles. We also detected a quadratic association of inflammation with postpartum DMI and BW such that cows in Q2 and Q3 also had generally lower postpartum DMI and BW compared with cows in Q1. There was a tendency for a $\mathrm{Q} \times$ time interaction for milk yield and $\mathrm{Q} \times$ time interactions for $3.5 \%$ fat-corrected milk and energy-corrected milk yields; quadratic relationships suggested decreased milk yield for Q2 and Q3 cows. We also found $\mathrm{Q} \times$ parity and $\mathrm{Q} \times$ time interactions for plasma glucose and insulin concentrations, suggesting alterations with differing degrees of inflammation. There was also a $\mathrm{Q} \times$ time interaction for plasma nonesterified fatty acids concentration. In addition, alterations in liver triglyceride and glycogen contents for cows with inflammation as well as alterations in $\left[1-{ }^{14} \mathrm{C}\right]$ propionate oxidation in vitro were observed. Although we observed limited effects of inflammation on neutrophil and monocyte phagocytosis at d 7 postpartum, inflammation appeared to alter neutrophil and monocyte oxidative burst. Overall, cows with any degree of elevated haptoglobin in the
\end{abstract}

Received April 9, 2015.

Accepted August 30, 2015.

${ }^{1}$ Corresponding author: tro2@cornell.edu first week after calving had alterations in both pre- and postpartum intake and postpartum metabolism.

Key words: early lactation, haptoglobin, energy metabolism, immune function

\section{INTRODUCTION}

During the immediate postpartum period, systemic inflammation can be identified by a marked increase in plasma acute phase protein concentrations (Bionaz et al., 2007; LeBlanc, 2012). Inflammation can develop upon pathogen recognition, as well as in response to trauma or stress, and is an essential component of the initial immune response for recruitment of immune cells to the affected tissues. Cytokines that are produced by immune cells [especially proinflammatory tumor necrosis factor- $\alpha$ (TNF- $\alpha)$ and IL-6] induce the production and release of acute phase proteins (e.g., haptoglobin, Hp) from the liver. Haptoglobin has been used as a marker of systemic inflammation in transition dairy cows, as it is elevated during the immediate postpartum period (Huzzey et al., 2009, 2011; Galvão et al., 2010). Elevated postpartum Hp has been associated with the occurrence of metritis (Huzzey et al., 2009; Galvão et al., 2010), greater risk for developing a metabolic disorder within $30 \mathrm{~d}$ postpartum (Huzzey et al., 2011), and decreased milk production (Huzzey et al., 2012).

In human patients with severe sepsis or major trauma, resting energy expenditure increases to $40 \%$ above normal and continues to be elevated for $3 \mathrm{wk}$ after the onset of illness (Plank and Hill, 2000). These data suggest that an immune disturbance increases the energy maintenance requirement. Negative energy balance (NEB) has been negatively correlated with both energy status (Galvão et al., 2010) and neutrophil function (Hammon et al., 2006). Together these data suggest that insufficient energy availability impairs the ability of the animal to mount a sufficient immune response. However, the energetic cost of immune activation in dairy cows has not been well-studied, and further investigation is warranted.

Elevated TNF- $\alpha$ has been shown to decrease glucose production (Kettelhut et al., 1987) and decrease fatty 
acid oxidation (Nachiappan et al., 1994), likely leading to increased triglyceride accumulation in the liver, with further impairment of energy metabolism (Strang et al., 1998). Oral administration of cytokine IFN- $\alpha$ in late gestation resulted in increased plasma BHB concentrations during the first $2 \mathrm{wk}$ after calving (Trevisi et al., 2009), and injections of exogenous TNF- $\alpha$ for $7 \mathrm{~d}$ doubled liver triglyceride content in late-lactation dairy cows (Bradford et al., 2009). These data suggest that increased inflammation disrupts normal energy metabolism processes. In addition, delaying the postpartum inflammatory response with salicylate treatment altered the metabolic adaptations of early lactation dairy cows and led to increased glucose utilization by peripheral tissues after salicylate treatment ended (Farney et al., 2013), suggesting that inflammatory pathways are also involved in the homeorhetic adaptation to lactation.

Many of the studies that have utilized early postpartum Hp as a marker of inflammation in early lactation dairy cows have been large field studies with infrequent sampling points (Huzzey et al., 2011) or measured Hp association with specific disease outcomes of interest (Huzzey et al., 2009; Galvão et al., 2010; Yasui et al., 2014). Although excessive inflammation has been shown to be associated with negative downstream consequences, it is unclear how much or what type of inflammation is necessary for postpartum adaptation (Huzzey et al., 2011). This current study further evaluates associations between the severity of systemic inflammation during the early postpartum period and performance, energy metabolism, and immune function.

\section{MATERIALS AND METHODS}

\section{Animals and Treatments}

All animal procedures were approved by the Cornell University Institutional Animal Care and Use Committee before the onset of the experiment. Data from 70 Holstein cows (primiparous $\mathrm{n}=21$, multiparous $\mathrm{n}=$ 49) from the Cornell University Teaching and Research Center Dairy (Harford, NY) were used for this study. Cows were recruited to address the hypotheses from a separate experiment (McCarthy et al., 2015a,b) that evaluated responses to feeding strategy in the early lactation period (high starch vs. low starch diet during the first $21 \mathrm{~d}$ postpartum) and monensin supplementation $(0 \mathrm{mg}$ of monensin/d or $400 \mathrm{mg} / \mathrm{d}$ of monensin prepartum and $450 \mathrm{mg} / \mathrm{d}$ of monensin postpartum; Rumensin; Elanco Animal Health, Greenfield, IN) as the variables of interest; detailed diet descriptions are provided in McCarthy et al. (2015a). Briefly, all cows were fed the same prepartum diet (17.4\% starch, $42.9 \%$
NDF, $28.2 \%$ ADF, $13.0 \% \mathrm{CP}$ ) and either a high starch (26.2\% starch, $34.3 \%$ NDF, $22.7 \%$ ADF, $15.5 \%$ CP) or low starch $(21.5 \%$ starch, $36.9 \%$ NDF, $25.2 \%$ ADF, $15.4 \% \mathrm{CP}$ ) postpartum diet depending on treatment assignment for the first $21 \mathrm{~d}$ of lactation. On d 22 postpartum, all cows were fed the high starch diet until d 63 of lactation. Lactating cows were dried off at least 45 $\mathrm{d}$ before expected parturition and moved to the experimental tiestall barn 28 d before expected parturition; data were collected through d 63 of lactation.

\section{Data Collection, Sampling Procedures, and Analytical Methods}

All cows were milked 2 times daily for the 9-wk lactation phase of the trial, and daily milk yield was measured electronically. Daily milk yield was the sum of the 2 milkings, and weekly means of daily production were calculated. Weekly milk samples were collected from 2 consecutive milkings obtained over a 24 -h period. Individual milk samples were sent to a commercial laboratory for analysis of milk composition (Dairy One, Ithaca, NY) as described by McCarthy et al. (2015a). Weekly yields of milk components were calculated, as well as yields of FCM $[3.5 \% \mathrm{FCM}=(0.432 \times$ milk $\mathrm{kg})$ $+(16.216 \times$ fat $\mathrm{kg})]$ and $\mathrm{ECM}[(0.327 \times$ milk kg $)+$ $(12.95 \times$ fat $\mathrm{kg})+(7.65 \times$ true protein $\mathrm{kg})]$.

Cows were housed in individual tiestalls and fed once daily for ad libitum intake at $0700 \mathrm{~h}$ in amounts targeted to provide 2 to $3 \mathrm{~kg}$ (wet weight) of refusals. Refusals for each cow were removed daily before feeding, weighed, and recorded. All ingredients were sampled weekly for determination of DM content to adjust ration formulation. Weekly means of daily DMI were calculated before statistical analysis.

All cows were weighed once weekly and BCS were assigned for all cows weekly by 2 scorers using a 5 -point system (Wildman et al., 1982), and scores were averaged before statistical analysis. Daily observations and general health records were maintained throughout the study. Prepartum and postpartum energy balance calculations were determined according to NRC (2001) equations as described in McCarthy et al. (2015a).

\section{Plasma Sampling and Analyses}

Blood samples were collected via venipuncture of the coccygeal vessels using heparinized Vacutainer tubes (Becton Dickinson, Franklin Lakes, NJ) $1 \mathrm{~h}$ before feeding. Blood samples were collected $1 \times /$ wk prepartum beginning during the week before commencement of prepartum treatment assignment (covariate), $3 \times /$ wk from calving through $21 \mathrm{~d}$ postpartum, and $1 \times / \mathrm{wk}$ 
from d 22 to 63 postpartum. Blood samples were placed on ice immediately following collection, and plasma was harvested after centrifugation of the blood at 1,300 $\times g$ for $15 \mathrm{~min}$ at $4^{\circ} \mathrm{C}$. There was very little hemolysis in the plasma samples collected. Plasma was stored at $-20^{\circ} \mathrm{C}$ until subsequent analysis for $\mathrm{Hp}$, glucose, insulin, nonesterified fatty acids (NEFA), and BHB.

Plasma concentrations of Hp were analyzed by enzymatic analysis using a commercial kit that measured haptoglobin-hemoglobin complex by estimated differences in peroxidase activity (Haptoglobin Assay, kit no. TP801, Tridelta Diagnostics Ltd., Morris Plains, NJ). Plasma concentrations of glucose were determined by an enzymatic analysis (glucose oxidase; protocol from kit 510-A, Sigma-Aldrich; St. Louis, MO) using commercial products (PGO Enzyme Preparation and $o$-dianisidine dihydrochloride). Plasma concentrations of NEFA also were analyzed by enzymatic analysis (HR Series NEFA HR (2), Wako Pure Chemical Industries, Osaka, Japan). Plasma concentrations of BHB were analyzed by enzymatic analysis (BHB dehydrogenase) using commercial products [NAD and Tris(hydroymethyl) aminomethane, Sigma-Aldrich; 3-hydroxybutyrate dehydrogenase, Roche Diagnostics Co., Indianapolis, IN]. All spectrophotometric measurements were conducted using a Versamax tunable microplate reader (Molecular Devices, Sunnyvale, CA). Inter- and intraassay variation was maintained at $<10 \%$ for all enzymatic analyses. Plasma concentrations of insulin were determined by double-antibody RIA (Porcine Insulin RIA cat. no. PI-12K, Linco Research/Millipore, St. Charles, MO), with a reported specificity to bovine insulin of $90 \%$. Inter- and intraassay coefficients of variation were 13.3 and $13.5 \%$, respectively.

\section{Liver Biopsy, Liver Metabolic Incubations, and Liver Composition}

Liver tissue was sampled via percutaneous trocar biopsy (Veenhuizen et al., 1991) from cows under local anesthesia on $\mathrm{d} 7$ ( \pm 4 range; $1.6 \mathrm{SD}$ ) relative to parturition. Biopsies were obtained from 37 multiparous cows and 17 primiparous cows. After blotting the liver tissue to remove excess blood and connective tissue, a portion of the sample was immersed in ice-cold PBS (0.015 $M ; 0.9 \% \mathrm{NaCl}, \mathrm{pH} 7.4)$ and transported to the laboratory within $45 \mathrm{~min}$ of tissue collection for the in vitro experiment. The remaining portion of the liver sample was snap-frozen in liquid nitrogen and stored at $-80^{\circ} \mathrm{C}$ until analysis for triglyceride and glycogen content.

Hepatic capacities for conversion of $\left[1-{ }^{14} \mathrm{C}\right]$ propionate $(1 \mu \mathrm{Ci}$ per flask $)$ in Krebs-Ringer bicarbonate medium (final substrate concentration of $10 \mathrm{mM}$ ) to $\mathrm{CO}_{2}$ and glucose were measured in triplicate flasks using tissue slices (60 to $80 \mathrm{mg}$ ) according to procedures described in McCarthy et al. (2015b). Liver triglyceride content was determined using the Folch extraction method (Folch et al., 1957) followed by a colorimetric method based upon the Hantzsch condensation for estimating serum triglyceride (Fletcher, 1968) with modifications described by Foster and Dunn (1973). Glycogen content of liver was determined according to the procedures described by Bernal-Santos et al. (2003).

\section{Phagocytosis, Oxidative Burst, and Flow Cytometric Analyses}

Blood samples were obtained from each cow via coccygeal blood vessel puncture at $8 \mathrm{~d}( \pm 2.5 \mathrm{SD} ; \pm 6 \mathrm{~d}$ range) postpartum. Phagocytosis was analyzed using a commercial kit (Phagotest, Glycotope Biotechnology, Heidelberg, Germany). Briefly, heparinized and mixed whole blood ( $100 \mu \mathrm{L}$ per test) was pipetted into the bottom of two 12- $\times 75$-mm test tubes (Becton Dickinson Biosciences, San Jose, CA). Opsonized fluorescein isothiocyanate-labeled Escherichia coli $(20 \mu \mathrm{L}$ per test) was added to the whole blood samples. After gently vortexing, a control sample was left on ice while a test sample was incubated for $10 \mathrm{~min}$ at $37.0^{\circ} \mathrm{C}$ in a water bath for $15 \mathrm{~min}$. At the end of the incubation time, all samples were taken out of the water bath and placed on ice simultaneously to stop phagocytosis. Quenching solution $(100 \mu \mathrm{L})$ was then added to quench the fluorescence of bacteria that were attached but not internalized into phagocytes. The samples were washed twice with $3 \mathrm{~mL}$ of wash solution and centrifuged at $250 \times g$ for $10 \mathrm{~min}$ at $4^{\circ} \mathrm{C}$ after each washing, and the supernatant was discarded. Erythrocytes in the samples were lysed and leukocytes fixed with the addition of $2 \mathrm{~mL}$ of the kit's lysing solution for $20 \mathrm{~min}$ at room temperature. After 2 wash steps (centrifugation for 5 min at $250 \times g$, $4^{\circ} \mathrm{C}$ ), the supernatant was discarded and DNA staining solution $(200 \mu \mathrm{L})$ was added, followed by incubation for $10 \mathrm{~min}$ on ice (light protected). Flow cytometry was performed within 60 min after the incubation.

Oxidative burst activity was analyzed using a commercial kit (Phagoburst, Glycotope Biotechnology). Briefly, heparinized and mixed whole blood $(100 \mu \mathrm{L}$ per test) was pipetted into the bottom of four $12-\times$ 75-mm test tubes (Becton Dickinson Biosciences). For activation, the following solutions $(20 \mu \mathrm{L}$ per tube) were added to whole blood: wash solution as a negative control (tube \#1); opsonized (nonlabeled) E. coli (tube \#2); chemotactic peptide $N$-formyl-MetLeuPhe solution as a low physiological stimulus (tube \#3); and 
Table 1. Distribution of cows based on highest haptoglobin concentration during $\mathrm{d} 1$ to 7 postpartum

\begin{tabular}{|c|c|c|c|c|}
\hline \multirow[b]{2}{*}{ Group } & \multicolumn{4}{|c|}{ Inflammation quartile ${ }^{1}$} \\
\hline & 1 & 2 & 3 & 4 \\
\hline \multicolumn{5}{|c|}{$\begin{array}{l}\text { Primiparous cows } \\
\text {. }\end{array}$} \\
\hline No. & 2 & 3 & 10 & 6 \\
\hline Percentage & 9.5 & 14.3 & 47.6 & 28.6 \\
\hline \multicolumn{5}{|c|}{ Multiparous cows } \\
\hline No. & 15 & 15 & 7 & 12 \\
\hline Percentage & 30.6 & 30.6 & 14.3 & 24.5 \\
\hline Total, no. & 17 & 18 & 17 & 18 \\
\hline
\end{tabular}

${ }^{1}$ Quartile $1=0.18-0.59$, quartile $2=0.60-1.14$, quartile $3=1.15-2.05$, quartile $4=2.06-2.50 \mathrm{~g}$ of haptoglobin/L during wk 1 postpartum. Quartile $\times$ parity (i.e., multiparous vs. primiparous) interaction: $P=$ 0.01 .

phorbol 12-myristate 13-acetate (PMA) solution as a strong stimulus (tube \#4). All tubes were mixed and incubated for $10 \mathrm{~min}$ at $37.0^{\circ} \mathrm{C}$ in a water bath. After incubation, the fluorogenic substrate solution $(20 \mu \mathrm{L})$ was added. The samples were vortexed thoroughly and incubated again for $10 \mathrm{~min}$ at $37.0^{\circ} \mathrm{C}$ in the water bath.
Erythrocytes in the samples were lysed and leukocytes fixed with the addition of $2 \mathrm{~mL}$ of the kit's lysing solution for $20 \mathrm{~min}$ at room temperature. After 2 wash steps (centrifugation for $5 \mathrm{~min}$ at $250 \times \mathrm{g}, 4^{\circ} \mathrm{C}$ ), the DNA staining solution $(200 \mu \mathrm{L})$ was added, followed by incubation for $10 \mathrm{~min}$ on ice (light protected in the ice bath). Flow cytometry was performed within $30 \mathrm{~min}$ after the incubation.

Flow cytometric analyses were conducted as previously described (Flaminio et al., 2002) using a BD FACScalibur (Becton Dickinson Biosciences) equipped with a 488- $\mu \mathrm{m}$ argon laser, 7600 Power Macintosh computer (Apple Inc., Cupertino, CA), and Cell Quest Analysis software (Becton Dickinson Biosciences). Leukocyte subpopulation (PMNL and monocytes) were displayed in a dot plot and gated according to size (forward light scatter) and granularity (90-degree side light scatter). Ten thousand events in the gated area were collected following the guidelines described in the commercial kits. The percent fluorescence-positive events (\% positive) and mean fluorescence intensity (MFI, which correlates with the mean number of bacteria ingested by a

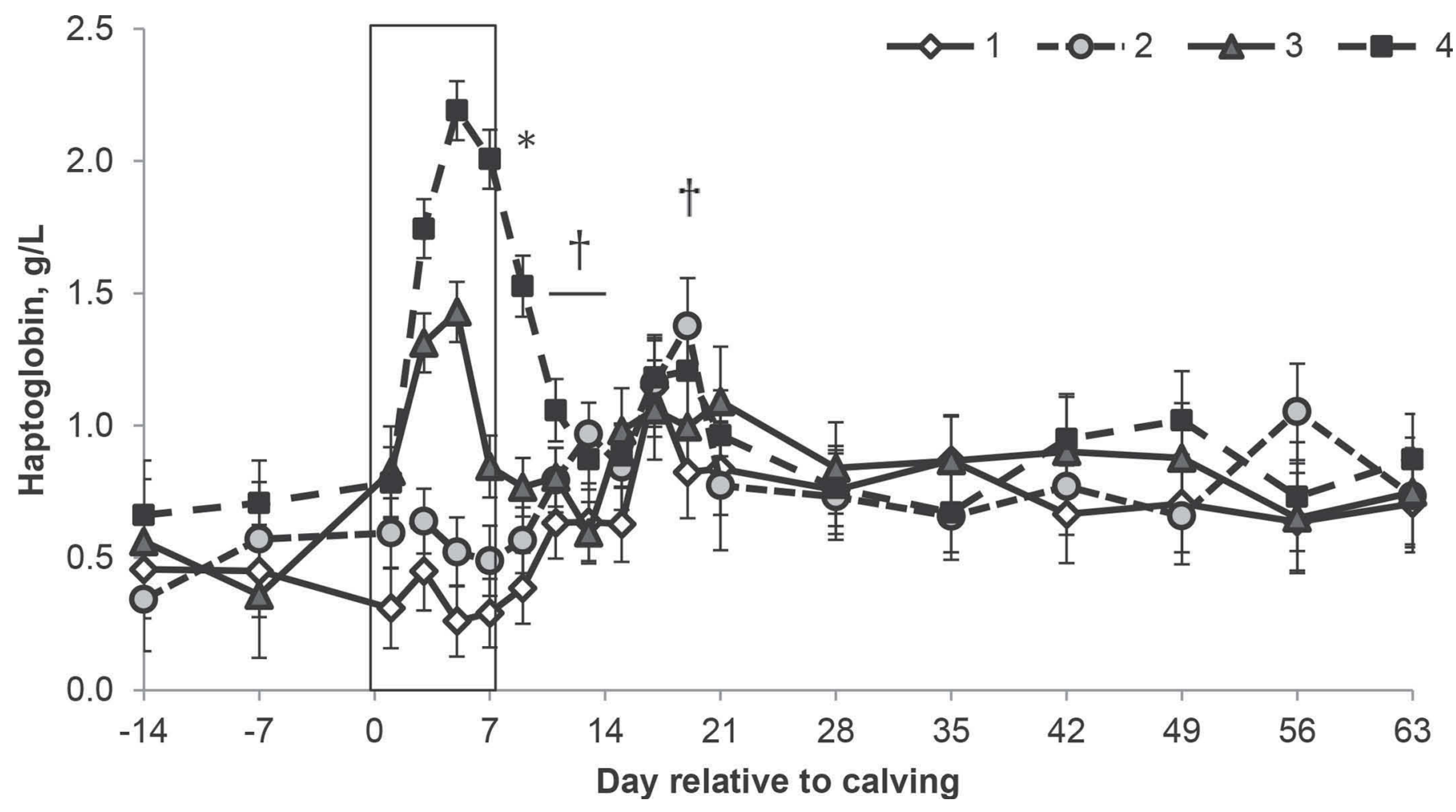

Figure 1. Periparturient haptoglobin concentrations for cows assigned to an inflammatory quartile (Q) based on the highest haptoglobin concentration during wk 1 postpartum $(\mathrm{Q} 1=0.18-0.59, \mathrm{Q} 2=0.60-1.14$, Q3 $=1.15-2.05, \mathrm{Q} 4=2.06-2.50 \mathrm{~g}$ of haptoglobin/L during wk 1 postpartum). The box indicates the window in which quartiles were defined. There was an interaction of $\mathrm{Q} \times$ time during the periparturient period $(P<0.001) . *$ Indicates a difference between inflammation quartiles $(P \leq 0.05) ; \dagger$ indicates a tendency for differences between inflammation quartiles $(0.05<P \leq 0.15)$ within sampling week. Error bars represent SEM. 
single phagocyte or the mean oxidative burst activity of a single phagocyte; Moya et al., 2008) were recorded for E. coli and PMA activation in each gated area (PMNL or monocyte). An index of overall phagocytic or oxidative burst activity was also calculated by multiplying the percentage of responding cells by the corresponding MFI: $[$ index $=($ positive $\%) \times(\mathrm{MFI})]$. Higher values for the index reflected higher phagocytic or oxidative burst activities (Canning et al., 1991). The control sample in each test was used to set the analysis threshold that indicated the positive and negative cell populations.

\section{Blood Neutrophil Glycogen}

Blood samples were obtained from each cow via coccygeal blood vessel puncture at $8 \mathrm{~d}$ postcalving. The PMNL were isolated using Ficoll 1083 density centrifugation as previously described (Galvão et al., 2010) and frozen for later glycogen determination. Glycogen in PMNL was determined as previously described by Galvão et al. (2010). Briefly, glycogen was hydrolyzed to glucose using amyloglucosidase; available glucose was determined by reacting $50 \mu \mathrm{L}$ of supernatant with a 1-mL mixture of $1 \mathrm{~m} M$ ATP, $0.9 \mathrm{~m} M$ NADP, $5 \mu \mathrm{g}$ of glucose-6-phosphate dehydrogenase, $0.3 \mathrm{M}$ triethanolamine, and $4 \mathrm{mM} \mathrm{MgSO}$ and recording the appearance of NADPH after the addition of $5 \mu \mathrm{L}$ of hexokinase $(2 \mathrm{mg} / \mathrm{mL})$ as change in optical density at $340 \mathrm{~nm}$ on a spectrophotometer. This change in optical density was compared with a standard curve of glycogen, and results were expressed as micrograms of glycogen $/ 10^{6}$ PMNL. Spectrophotometric measurements were conducted using a Versamax tunable microplate reader (Molecular Devices).

\section{Statistical Analyses}

We were interested in evaluating the relationship between the severity of systemic inflammation (as measured by plasma Hp concentration) during the postpartum period and production performance, metabolism, and immune function. Statistical computations were performed using SAS software (version 9.3; SAS Institute Inc., Cary, NC). Cows were assigned to categorical quartiles $(\mathbf{Q} ; \mathrm{Q} 1=0.18-0.59, \mathrm{Q} 2=0.60-1.14, \mathrm{Q} 3=$ 1.15-2.05, and $\mathrm{Q} 4=2.06-2.50 \mathrm{~g}$ of $\mathrm{Hp} / \mathrm{L}$ ) based on the highest Hp concentration during wk 1 postpartum. We detected no effect of starch or monensin treatment on the distribution of cows to quartiles, so dietary treatment was not included in the model. Because quartiles were not equally spaced, PROC IML was used to obtain linear and quadratic contrast coefficients for mean quartile values. Linear and quadratic contrasts were tested for all measurements. Data analyzed over time were subjected to repeated-measures ANOVA using PROC MIXED of SAS and the REPEATED statement. Fixed effects included inflammation quartile, parity, time, and all 2-way interactions. The random effect was cow nested within inflammation quartile. Post hoc comparisons between groups at each time point were obtained. Four covariance structures were tested: compound symmetry, heterogeneous compound symmetry, first-order autoregressive, and heterogeneous first-order autoregressive, and the covariance structure that resulted in the smallest Akaike information criterion was used. Data for liver composition, in vitro metabolism, and immune function were subjected to ANOVA using the PROC MIXED procedure. Because data for liver composition, in vitro metabolism, and immune function were collected over a range of days, sampling day was included as a random variable in the

Table 2. Health events (no.) for cows with increasing inflammation as measured by the highest plasma haptoglobin concentration during the first week postcalving

\begin{tabular}{lllll}
\hline & \multicolumn{5}{c}{ Inflammation quartile $^{2}$} \\
\cline { 2 - 5 } Item $^{1}$ & 1 & 2 & 3 & 4 \\
\hline Hypocalcemia & 0 & 0 & 0 & 0 \\
$\quad$ Primiparous & 0 & 1 & 0 & 1 \\
$\quad$ Multiparous & 0 & 1 & 1 & 1 \\
$\quad$ Ketosis & 2 & 3 & 1 & 0 \\
$\quad$ Primiparous & & & & \\
$\quad$ Multiparous & 0 & 0 & 0 & 0 \\
$\quad$ Displaced abomasum & 0 & 0 & 0 & 0 \\
$\quad$ Primiparous & & & & \\
$\quad$ Multiparous & 0 & 0 & 1 & 0 \\
Retained placenta & 0 & 0 & 0 & 2 \\
$\quad$ Primiparous & & & & \\
$\quad$ Multiparous & 0 & 0 & 2 & 1 \\
$\quad$ Dystocia & 0 & 0 & 0 & 0 \\
$\quad$ Primiparous & & & & \\
$\quad$ Multiparous & 0 & 0 & 2 & 0 \\
$\quad$ Primis & 2 & 1 & 1 & 1 \\
$\quad$ Multiparous & 4 & 6 & 8 & 6 \\
\hline Total health disorders &
\end{tabular}

${ }^{1}$ Disorders defined as follows: hypocalcemia $=$ cows that had decreased body temperature and were unable to stand were treated with calcium dextrose; ketosis $=$ cows that had rapid decreases in milk production and DMI were checked with Precision Xtra blood meter (Abbott Laboratories, Abbott Park, IL), readings $\geq 2.6 \mathrm{mmol} / \mathrm{L}$ were treated with dextrose and propylene glycol; displaced abomasum $=$ movement of the fourth compartment of the stomach to a location on the right or left side of the cow and detected by auscultating a "ping" sound with finger percussion; retained placenta $=$ cows that retained afterbirth for $>24$ h; dystocia $=$ cows that had a calving ease score of $>3$; mastitis $=$ cows with abnormal milk, or inflamed quarter were treated with antibiotics.

${ }^{2}$ Quartile $1=0.18-0.59$, quartile $2=0.60-1.14$, quartile $3=1.15-2.05$, quartile $4=2.06-2.50 \mathrm{~g}$ of haptoglobin/L during wk 1 postpartum. 
INFLAMMATION IN THE POSTPARTUM COW

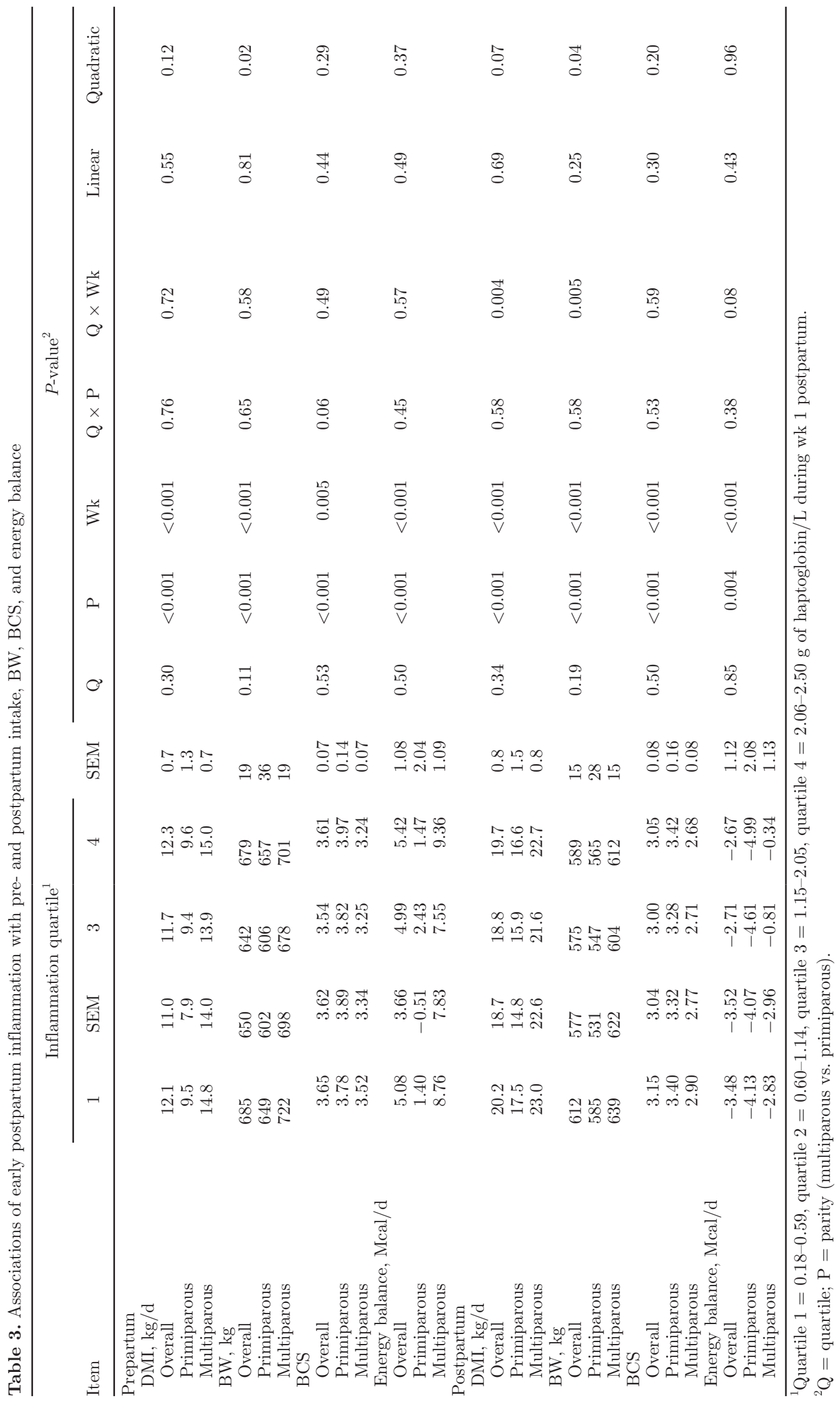


model. The degrees of freedom for all PROC MIXED were estimated using the Kenward-Roger option in the model statement. The fixed effect was inflammation quartile. Statistical significance was declared at $P \leq$ 0.05 and trends were discussed at $0.05<P \leq 0.15$.

\section{RESULTS}

\section{Quartile Distribution}

All cows were categorized into quartiles $(\mathrm{Q} 1=$ $0.18-0.59, \mathrm{Q} 2=0.60-1.14, \mathrm{Q} 3=1.15-2.05$, and $\mathrm{Q} 4$ $=2.06-2.50 \mathrm{~g} \mathrm{Hp} / \mathrm{L}$ ) based on the highest Hp concentration during wk 1 postpartum (Table 1). Although cows were classified into inflammatory quartiles based on very early postpartum $\mathrm{Hp}$ concentrations, this early classification resulted in distinctive Hp inflammatory responses through the first 9 wk of lactation (Figure 1). Cows in Q1 had very little inflammation during wk 1 postpartum, although they exhibited an increase in Hp during wk 2 with a peak in Hp concentration in wk 3. Cows in Q2 also had similar delays in Hp elevation until wk 3 postpartum. Cows in Q3 had an elevation of Hp in wk 1, but maintained similar Hp levels to other cows through d 63 postpartum, whereas cows in Q4 had an acute early-lactation inflammatory response with a return to levels similar to the other quartiles by wk 3 postpartum. As a subset of cows had liver biopsies on d 7 postpartum ( $\pm 1.6 \mathrm{SD}$; equal distribution of cows biopsied among quartiles), the second peak in $\mathrm{Hp}$ was likely a result of the biopsy (Figure 1). Occurrences of health disorders for all cows are presented in Table 2. Because of the relatively small number of cows enrolled in this data set, these data are reported for informational purposes only.

\section{Periparturient DMI, BW, BCS, NEB, Milk Production, and Milk Production Efficiency}

We detected a tendency for a quadratic relationship of postpartum inflammatory status with prepartum DMI $(P=0.12$; Table 3$)$, such that cows in Q2 had the largest decrease in DMI as parturition approached. There was a $\mathrm{Q} \times$ time interaction for postpartum DMI

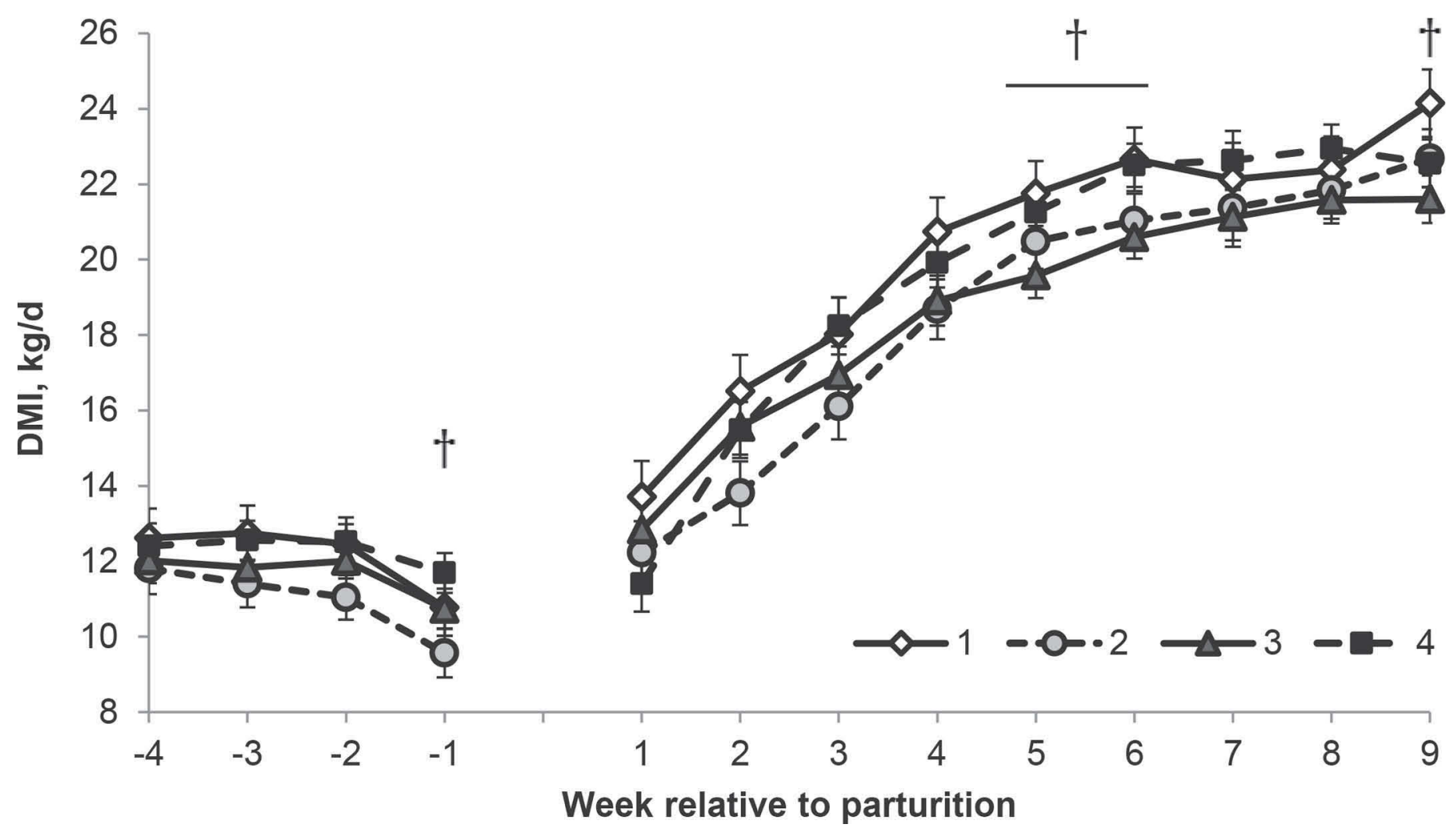

Figure 2. Least squares means for periparturient DMI for cows assigned to an inflammatory quartile (Q) based on the highest haptoglobin concentration during wk 1 postpartum $(\mathrm{Q} 1=0.18-0.59, \mathrm{Q} 2=0.60-1.14$, Q3 $=1.15-2.05, \mathrm{Q} 4=2.06-2.50 \mathrm{~g}$ of haptoglobin/L during wk 1 postpartum). The $P$-value for the main effect of inflammation was 0.30 during the prepartum period and 0.34 during the postpartum period. There was an interaction of $\mathrm{Q} \times$ time postpartum $(P=0.004)$. ${ }^{*}$ Indicates a difference between inflammation quartiles $(P \leq 0.05) ; \dagger$ indicates a tendency for differences between inflammation quartiles $(0.05<P \leq 0.15)$ within sampling week. Error bars represent SEM. 
$(P=0.004$; Figure 2$)$ and a tendency for a quadratic relationship $(P=0.07)$ such that cows in Q2 and Q3 had decreases in DMI compared with cows in Q1 and Q4. We detected a tendency for an effect of postpartum inflammation on prepartum BW $(P=0.11)$ and a quadratic relationship $(P=0.02)$ such that cows in Q2 and Q3 had lower prepartum BW compared with cows in other quartiles. There was a $\mathrm{Q} \times$ time interaction for postpartum BW $(P=0.005$; Figure 3$)$ and a quadratic relationship $(P=0.04)$ such that cows with postpartum inflammation had lower postpartum BW. We detected a tendency for a $\mathrm{Q} \times$ parity interaction $(P$ $=0.06)$ on prepartum BCS; however, differences were slight and there was no interaction of inflammation on postpartum BCS $(\mathrm{Q} \times$ parity; $P=0.53)$. Although we found no effect of postpartum inflammation on prepartum energy balance, there was a tendency for a $\mathrm{Q} \times$ time interaction for postpartum EB $(P=0.08$; Figure 4).

Milk yield and feed efficiency results are presented in Table 4 . We detected a tendency for a $\mathrm{Q} \times$ time interaction on milk yield $(P=0.06$; Figure 5$)$ such that differences between inflammatory groups were more pronounced earlier in lactation. Similar Q $\times$ time interactions were found for $3.5 \% \mathrm{FCM}(P=0.03)$ and ECM $(P=0.01)$. There was a quadratic tendency for both $3.5 \%$ FCM $(P=0.07)$ and ECM $(P=0.10)$ such that cows in Q2 and Q3 tended to have lower yields of FCM and ECM. We detected a tendency for a $\mathrm{Q} \times$ parity interaction for MUN $(P=0.11)$, and primiparous cows in Q1 had the lowest MUN. There tended to be a $\mathrm{Q} \times$ time interaction for SCS $(P=0.08$; data not shown $)$ and a linear relationship $(P=0.05)$ suggested increasing SCS with increased inflammation, although this difference appeared to occur only in wk 1 . There was no effect of inflammation on feed efficiency measured as either milk:DMI or ECM:DMI.

\section{Periparturient Plasma Metabolites}

Periparturient plasma metabolites are presented in Table 5 and Figure 6. We detected a tendency for an effect of inflammation on periparturient plasma glucose concentration $(P=0.12)$ that seemed to be driven by a

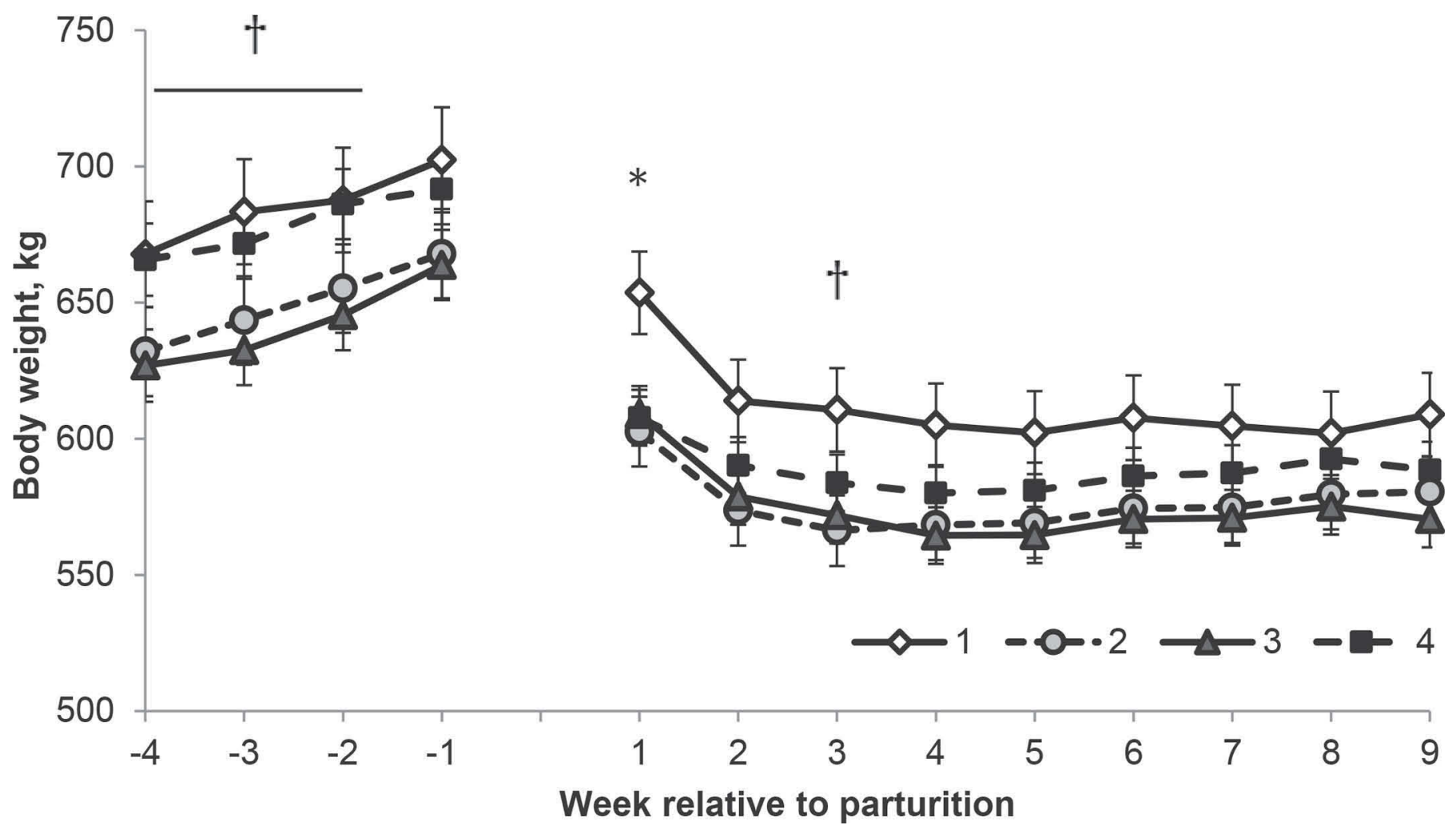

Figure 3. Least squares means for periparturient BW (kg/d) for cows assigned to an inflammatory quartile (Q) based on the highest haptoglobin concentration during wk 1 postpartum $(\mathrm{Q} 1=0.18-0.59, \mathrm{Q} 2=0.60-1.14, \mathrm{Q} 3=1.15-2.05, \mathrm{Q} 4=2.06-2.50 \mathrm{~g}$ of haptoglobin/L during wk 1 postpartum). The $P$-value for the main effect of inflammation was 0.11 prepartum and 0.19 during the postpartum period. There was an interaction of $\mathrm{Q} \times$ time during the postpartum period $(P=0.005)$. ${ }^{*}$ Indicates a difference between inflammation quartiles $(P \leq 0.05)$; $\dagger$ indicates a tendency for differences between inflammation quartiles $(0.05<P \leq 0.15)$ within sampling week. Error bars represent SEM. 
$\mathrm{Q} \times$ parity $(P=0.003)$ and a $\mathrm{Q} \times$ time interaction $(P$ $=0.03$, Figure $6 \mathrm{~A}$ ). As such, primiparous cows in $\mathrm{Q} 2$ had the lowest plasma glucose concentrations, although there were only 3 primiparous cows in this quartile. There was a similar $\mathrm{Q} \times$ parity $(P=0.10)$ and $\mathrm{Q}$ $\times$ time $(P<0.001$, Figure $6 \mathrm{~B})$ interaction for plasma insulin, and primiparous cows in Q2 had the lowest plasma insulin concentrations. We found a $\mathrm{Q} \times$ time interaction $(P=0.02$; Figure $6 \mathrm{C})$ for plasma NEFA, and it appears that cows with increasing inflammation had lower plasma NEFA concentrations. Although we detected no association of inflammation or interaction of $\mathrm{Q} \times$ time on plasma BHB concentration in the current study, there were treatment differences for individual sample days, in which cows in Q1 and Q2 had higher peaks in BHB compared with Q3 and Q4 cows (Figure 6D).

\section{Liver Composition and In Vitro Liver Metabolism}

We detected a tendency for a quadratic association of inflammation with liver triglyceride content at d 7 post- partum, such that cows in Q1 and Q4 tended to have the highest triglyceride content $(P=0.02$; Table 6$)$. Inflammation had an effect on liver glycogen content, which appeared to be driven by a tendency for a $\mathrm{Q} \times$ parity interaction $(P=0.09)$ such that primiparous Q2 cows and multiparous Q4 cows had the lowest glycogen content at $\mathrm{d} 7$ postpartum.

We detected an association of inflammation on in vitro conversion of $\left[1-{ }^{14} \mathrm{C}\right]$ propionate to $\mathrm{CO}_{2}(P=0.05$, Table 6$)$ and a quadratic tendency $(P=0.10)$ such that cows in Q3 had lower propionate oxidation compared with cows in other quartiles. In experiments using labeled isotopes, the $\left[1-{ }^{14} \mathrm{C}\right]$ propionate label randomizes in the tricarboxylic acid cycle such that every $1 \mathrm{~mol}$ of $\left[1-{ }^{14} \mathrm{C}\right]$ propionate that is directed toward oxaloacetate should yield $0.5 \mathrm{~mol}$ of radiolabeled $\mathrm{CO}_{2}$ and $0.5 \mathrm{~mol}$ of radiolabeled glucose (Knapp et al., 1992). Any increase in this ratio of labeled glucose to $\mathrm{CO}_{2}$ would suggest an increase in the efficiency of utilization of propionate for gluconeogenesis; however, we detected no relationship of inflammation with the ratio of glucose to $\mathrm{CO}_{2}$ in the current study (Table 6).

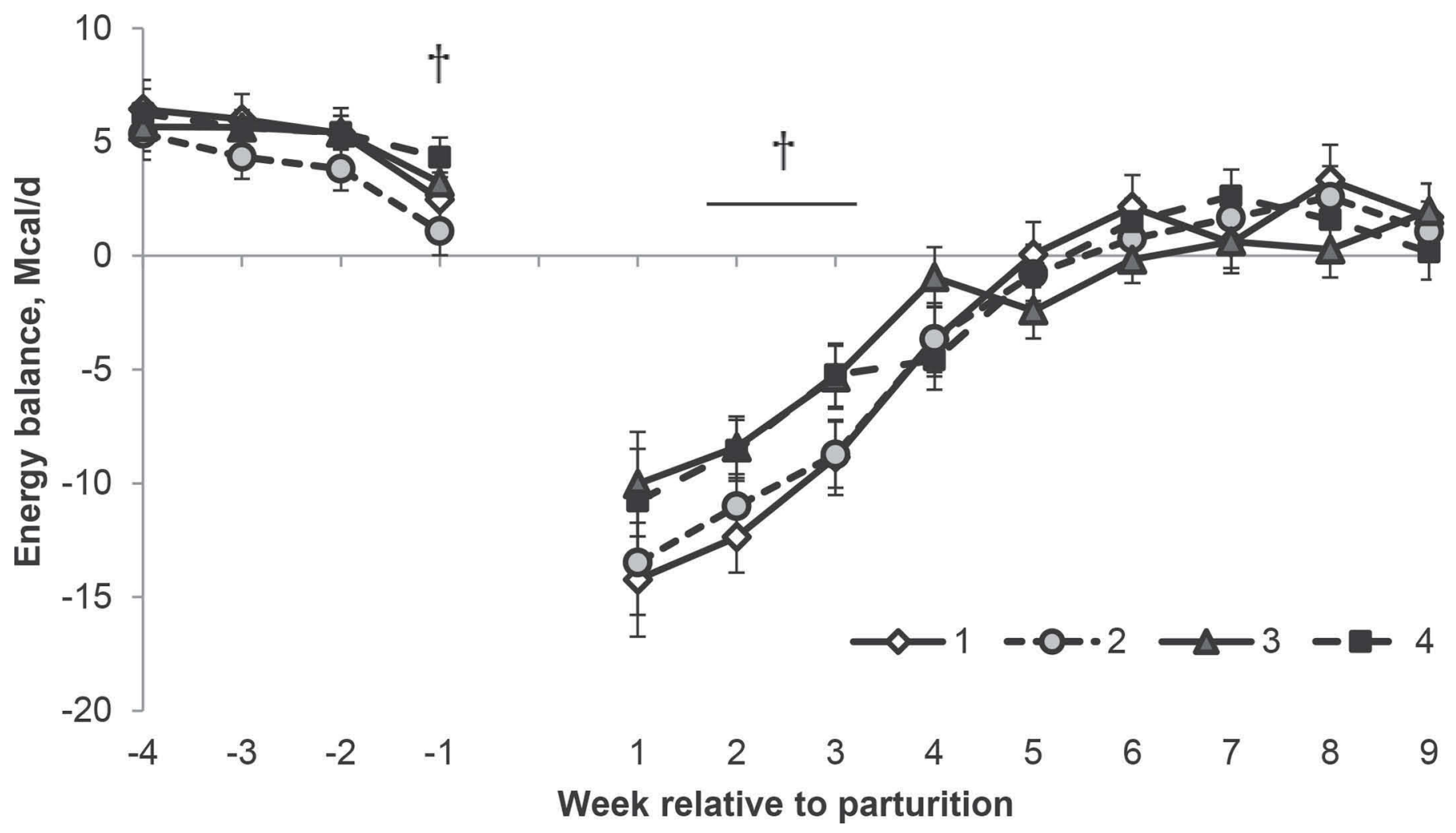

Figure 4. Least squares means for periparturient energy balance (Mcal/d) for cows assigned to an inflammatory quartile (Q) based on the highest haptoglobin concentration during wk 1 postpartum $(\mathrm{Q} 1=0.18-0.59, \mathrm{Q} 2=0.60-1.14, \mathrm{Q} 3=1.15-2.05, \mathrm{Q} 4=2.06-2.50 \mathrm{~g}$ of haptoglobin/L during wk 1 postpartum). The $P$-value for the main effect of inflammation was 0.50 prepartum and 0.85 postpartum. There was a tendency for an interaction of $\mathrm{Q} \times$ time during the postpartum period $(P=0.08)$. ${ }^{*}$ Indicates a difference between inflammation quartiles $(P \leq$ $0.05) ; \dagger$ indicates a tendency for differences between inflammation quartiles $(0.05<P \leq 0.15)$ within sampling week. Error bars represent SEM. 
INFLAMMATION IN THE POSTPARTUM COW

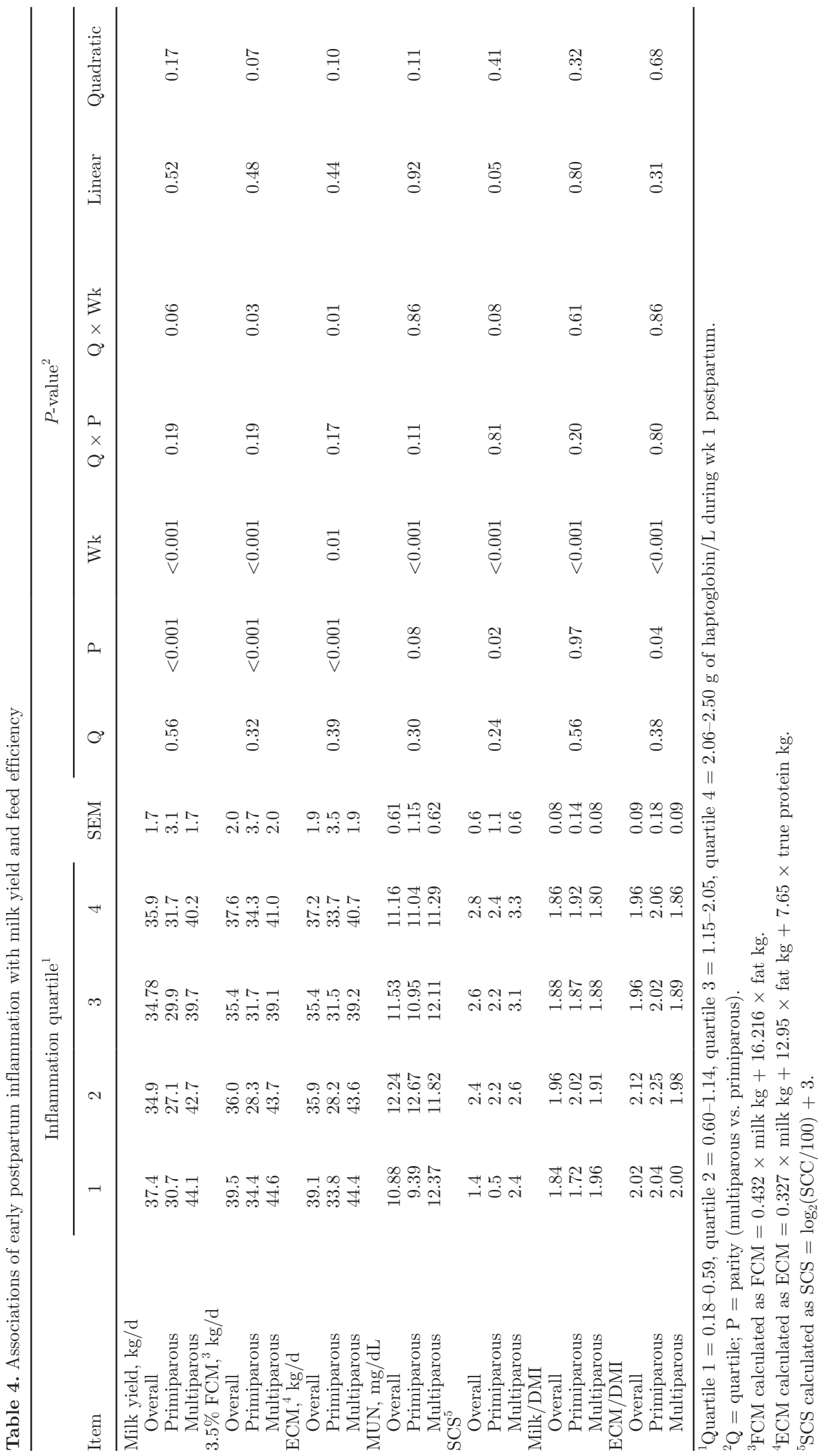




\section{Immune Function}

Relationships of inflammatory quartile with measures of immune cell phagocytosis and oxidative burst at $d$ 7 postpartum are presented in Tables 7 and 8. Cows in all quartiles had similar neutrophil phagocytosis; however, we found a tendency for a $\mathrm{Q} \times$ parity interaction $(P=0.12$, Table 7$)$ for percentage of neutrophils involved in phagocytosis such that primiparous cows in Q3 appeared to have less neutrophils involved in phagocytosis than primiparous cows in other quartiles. There was no relationship of inflammatory quartile with monocyte phagocytosis (Table 7). We found a quadratic relationship of inflammatory quartile with neutrophil and monocyte $E$. coli-stimulated oxidative burst such that cows in Q1 tended to have a higher percentage of $E$. coli-stimulated neutrophils involved in oxidative burst $(P=0.11$; Table 8$)$, and cows in Q1 tended to have a higher percentage of $E$. coli-stimulated monocytes involved in oxidative burst $(P=0.11$; Table $8)$. We identified a tendency for a relationship between inflammatory quartile and E. coli-stimulated monocyte oxidative burst index $(P=0.13$; Table 8$)$ and a quadratic interaction $(P=0.03)$ suggested that cows in Q2 and Q3 had a lower E. coli-stimulated monocyte oxidative burst index compared with cows in other quartiles. There was a relationship between inflammatory quartile and percentage of neutrophils involved in PMA-stimulated oxidative burst $(P=0.03$; Table 8$)$, suggesting that cows in Q2 had a lower percentage of neutrophils involved in oxidative burst. We detected a relationship between inflammatory quartile and neutrophil PMA-stimulated oxidative burst index $(P$ $=0.04$; Table 8 ), and the tendency for a $\mathrm{Q} \times$ parity interaction $(P=0.13)$ suggested that primiparous cows in Q2 and Q4 had a decreased index compared with other quartiles. There was a tendency for a relationship between inflammatory quartile and percentage of monocytes involved in PMA-stimulated oxidative burst $(P=0.12$; Table 8$)$. We found no association of inflammatory quartile with neutrophil glycogen content at $\mathrm{d}$ 7 postpartum (Table 9 ).

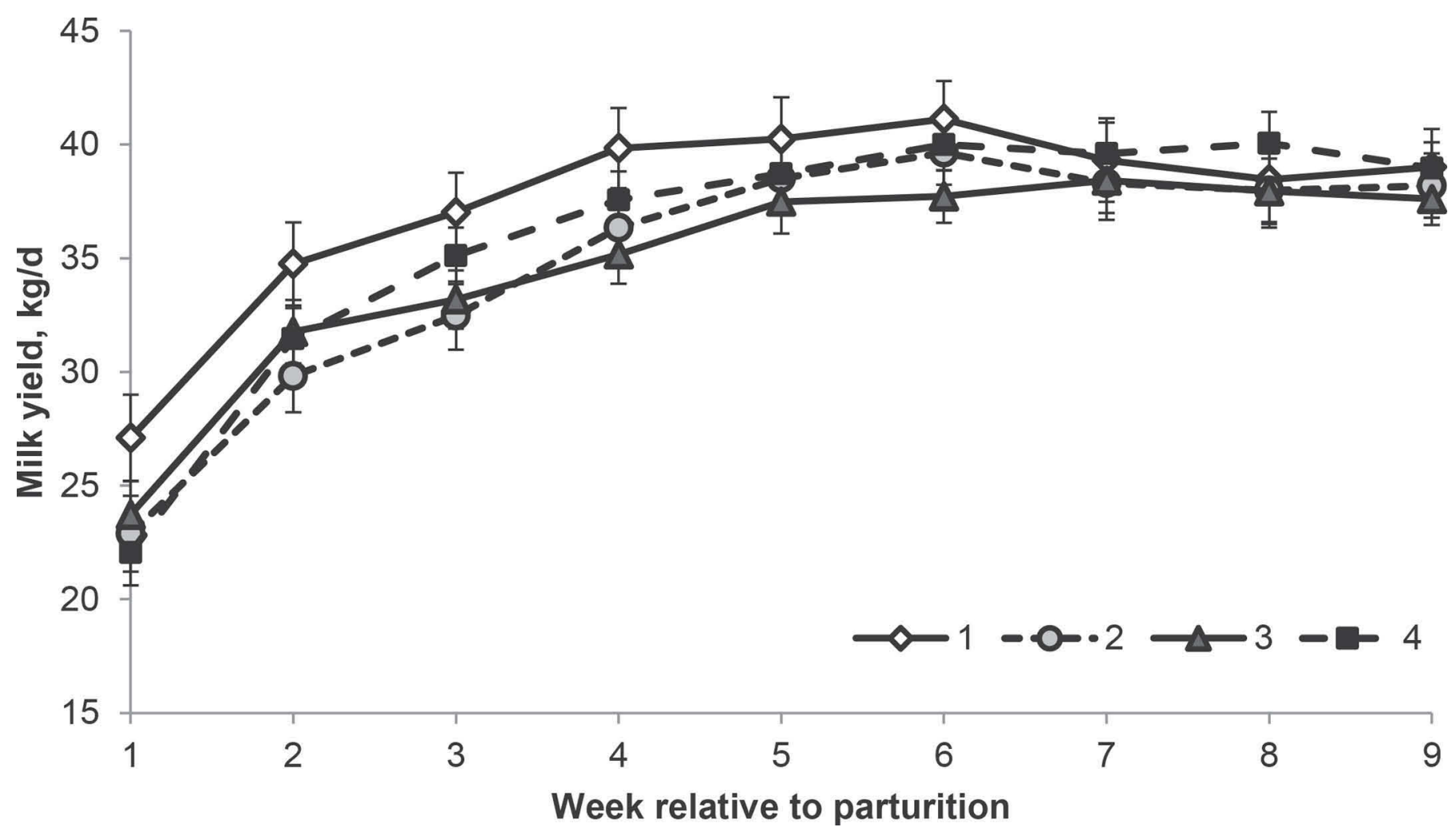

Figure 5. Least squares means for postpartum milk yield $(\mathrm{kg} / \mathrm{d})$ for cows assigned to an inflammatory quartile (Q) based on the highest haptoglobin concentration during wk 1 postpartum $(\mathrm{Q} 1=0.18-0.59, \mathrm{Q} 2=0.60-1.14, \mathrm{Q} 3=1.15-2.05, \mathrm{Q} 4=2.06-2.50 \mathrm{~g}$ of haptoglobin/L during wk 1 postpartum). The $P$-value for the main effect of inflammation was 0.56 . There was a tendency for an interaction of $\mathrm{Q} \times$ time $(P=$ 0.06). Error bars represent SEM. 


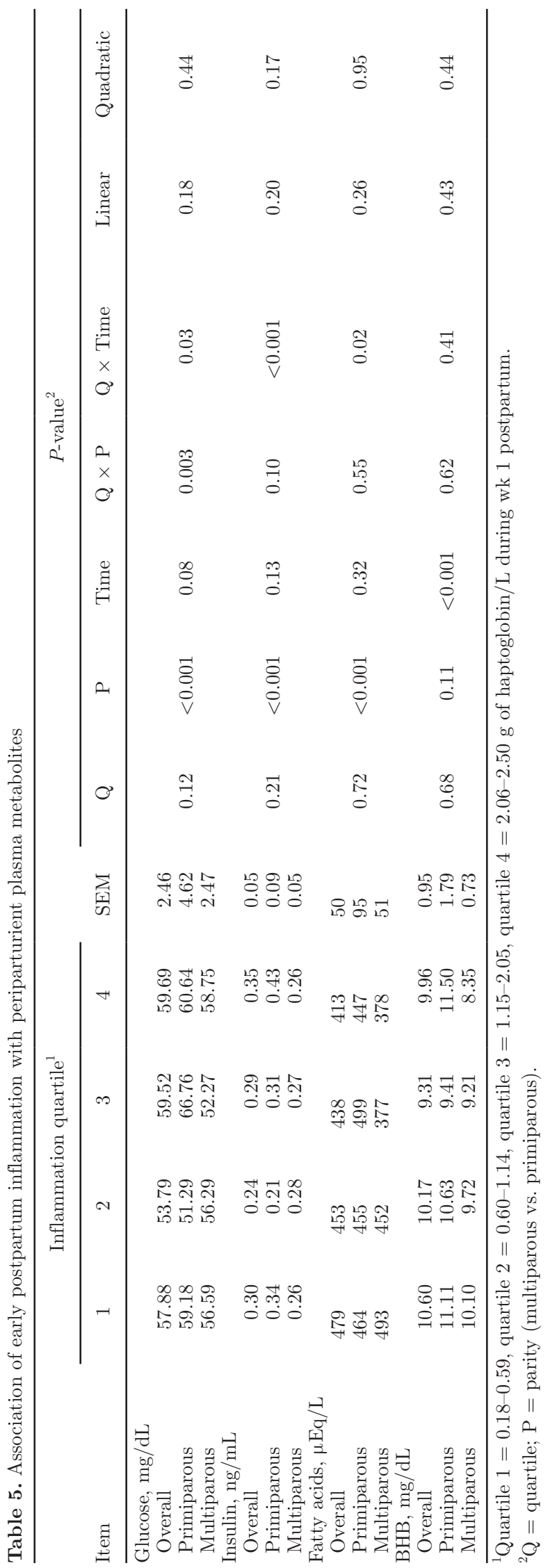

\section{DISCUSSION}

The objective of this study was to evaluate relationships between severity of systemic inflammation during the early postpartum period, using haptoglobin as a marker of inflammation, and performance, energy metabolism, and immune function. Elevated early postpartum Hp has been associated with the incidence of metritis (Galvão et al., 2010) and reductions in milk yield and reproductive function (Huzzey et al., 2012). In the current study, cows in Q3 and Q4 had Hp concentrations $>1.15 \mathrm{~g} / \mathrm{L}$, which is similar to the high $\mathrm{Hp}$ cutoff point of $1.1 \mathrm{~g} / \mathrm{L}$ during the first week of lactation established by Huzzey et al. (2011). Interestingly, we found very different responses in production performance for cows with any degree of early lactation inflammation in the current study (i.e., cows in Q2, Q3, and Q4). Although the mobilization of active neutrophils is one of the key defenses against infectious disease in dairy cows (Burvenich et al., 2003), monocytes have been shown to be more responsive to inflammatory stimulation during the transition period than during other physiological states, resulting in greater cytokine production (Sordillo et al., 1995). However, quadratic tendencies suggest that cows in Q2 and Q3 had decreased percentages of neutrophils and monocytes involved in oxidative burst as well as a decreased index of monocyte oxidative burst, perhaps indicating that Q2 and Q3 cows had an impaired early lactation immune response compared with Q4 cows.

Cows in Q2 had lower prepartum DMI compared with cows in other quartiles, which continued through the postpartum period. The decrease in prepartum DMI for cows in Q2 and the decrease in DMI for cows in Q2 and Q3 postpartum, along with decreased postpartum immune function indices, indicates that perhaps they did not have enough energy to mount a sufficient immune response during the immediate postpartum period, leading to observed postpartum alterations in metabolism and decreased productive performance. Although cows in Q4 had initially low DMI during the early postpartum period, they returned to similar intake compared with cows in Q1. However, cows in Q2 and Q3 had greater sustained reductions in DMI compared with cows in the other quartiles. Interestingly, there was a quadratic effect of prepartum BW, and cows in Q2 and Q3 had lower prepartum BW compared with cows in Q1 and Q4. This quadratic effect was also apparent during the postpartum period, with cows in Q2 and Q3 having reduced postpartum BW. Together, these results suggest that cows with postpartum inflammation experience reductions in DMI, perhaps because some of the pro-inflammatory cytokines that are secreted in response to an inflammatory event have been shown to 

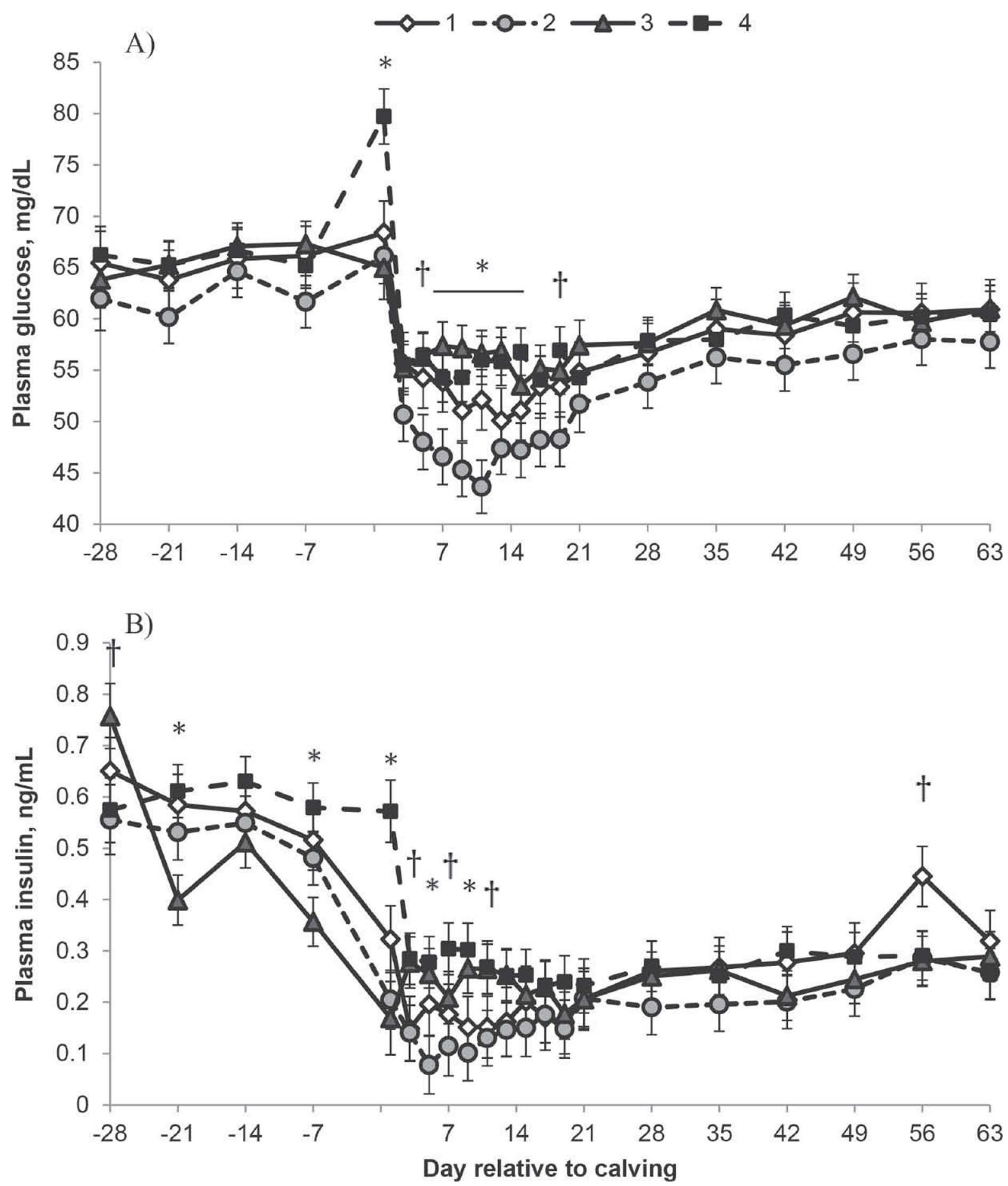

Figure 6. Least squares means for periparturient plasma glucose, insulin, fatty acids, and BHB concentrations for cows assigned to an inflammatory quartile $(\mathrm{Q})$ based on the highest haptoglobin concentration during wk 1 postpartum $(\mathrm{Q} 1=0.18-0.59, \mathrm{Q} 2=0.60-1.14, \mathrm{Q} 3=1.15-2.05$, $\mathrm{Q} 4=2.06-2.50 \mathrm{~g}$ of haptoglobin/L during wk 1 postpartum). (A) Periparturient plasma glucose concentrations. The $P$-value for the main effect of inflammation was 0.12 during the periparturient period; however, there was a $\mathrm{Q} \times$ time interaction for plasma glucose concentrations during the periparturient period $(P=0.03)$. (B) Periparturient plasma insulin concentrations. The $P$-value for the main effect of inflammation was 0.21 during the periparturient period; however, there was a $\mathrm{Q} \times$ time interaction for plasma insulin concentrations during the periparturient period $(P<0.001)$. (C) Periparturient plasma fatty acids concentrations. The $P$-value for the main effect of inflammation was 0.72 during the periparturient period; however, there was a $\mathrm{Q} \times$ time interaction for plasma fatty acids concentrations during the periparturient period $(P=$ 0.02). (D) Periparturient plasma BHB concentrations. There was no main effect of inflammation on BHB $(P=0.65)$ and no Q $\times$ time interaction for plasma BHB concentrations during the periparturient period $(P=0.41)$; however, there were differences on individual sampling days. * Indicates a difference between inflammation quartiles $(P<0.05)$; $\dagger$ indicates a tendency for differences between inflammation quartiles $(0.10$ $<P>0.05)$ within sampling day. Error bars represent SEM. 

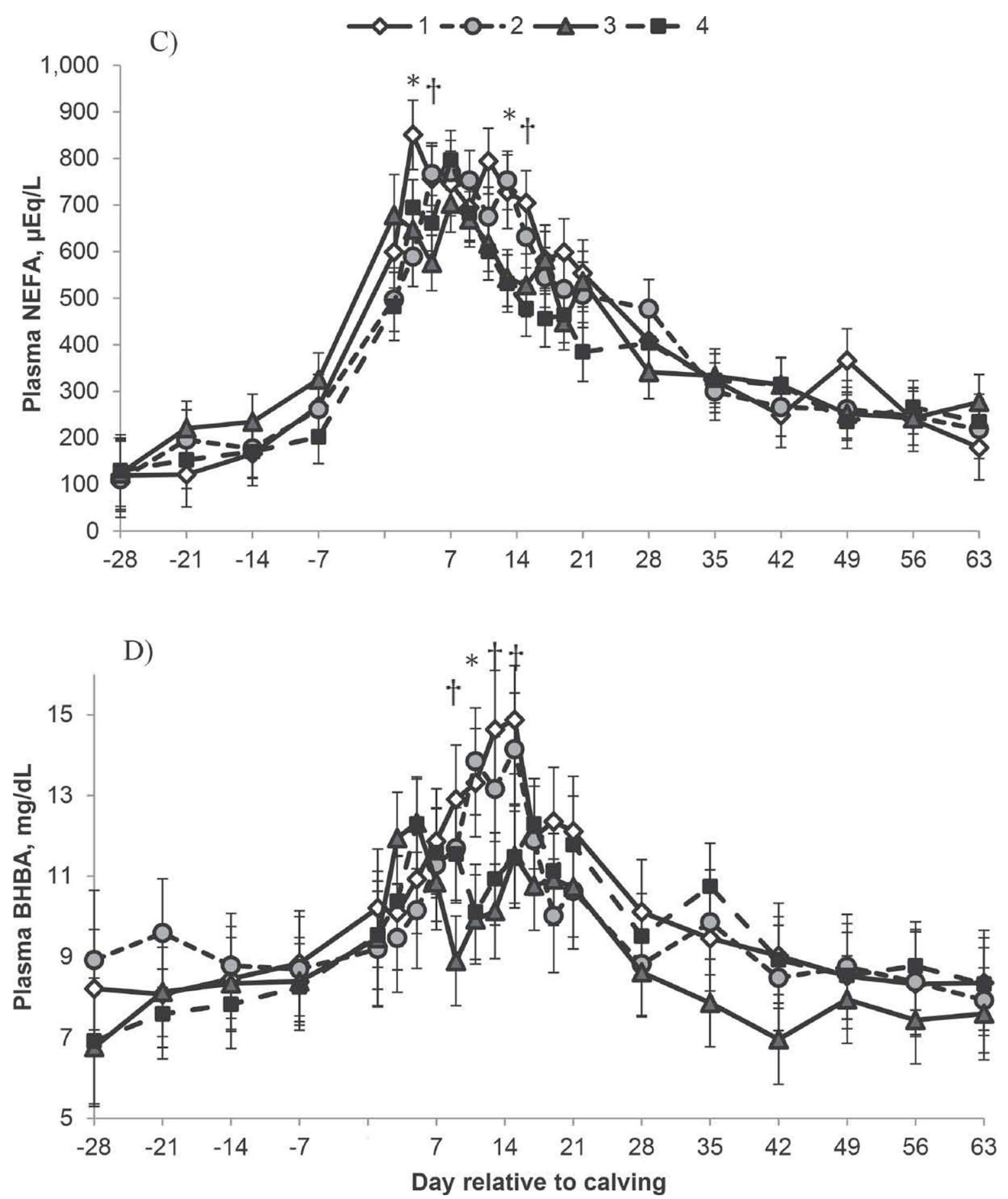

Figure 6 (Continued). Least squares means for periparturient plasma glucose, insulin, fatty acids, and BHB concentrations for cows assigned to an inflammatory quartile $(\mathrm{Q})$ based on the highest haptoglobin concentration during wk 1 postpartum $(\mathrm{Q} 1=0.18-0.59$, Q2 $=$ $0.60-1.14, \mathrm{Q} 3=1.15-2.05, \mathrm{Q} 4=2.06-2.50 \mathrm{~g}$ of haptoglobin/L during wk 1 postpartum). (A) Periparturient plasma glucose concentrations. The $P$-value for the main effect of inflammation was 0.12 during the periparturient period; however, there was a $\mathrm{Q} \times$ time interaction for plasma glucose concentrations during the periparturient period $(P=0.03)$. (B) Periparturient plasma insulin concentrations. The $P$-value for the main effect of inflammation was 0.21 during the periparturient period; however, there was a $\mathrm{Q} \times$ time interaction for plasma insulin concentrations during the periparturient period $(P<0.001)$. (C) Periparturient plasma fatty acids concentrations. The $P$-value for the main effect of inflammation was 0.72 during the periparturient period; however, there was a $\mathrm{Q} \times$ time interaction for plasma fatty acids concentrations during the periparturient period $(P=0.02)$. (D) Periparturient plasma BHB concentrations. There was no main effect of inflammation on BHB $(P=0.65)$ and no $\mathrm{Q} \times$ time interaction for plasma BHB concentrations during the periparturient period $(P=0.41)$; however, there were differences on individual sampling days. ${ }^{*}$ Indicates a difference between inflammation quartiles $(P<0.05)$; $\dagger$ indicates a tendency for differences between inflammation quartiles $(0.10<P>0.05)$ within sampling day. Error bars represent SEM. 
MCCARTHY ET AL.

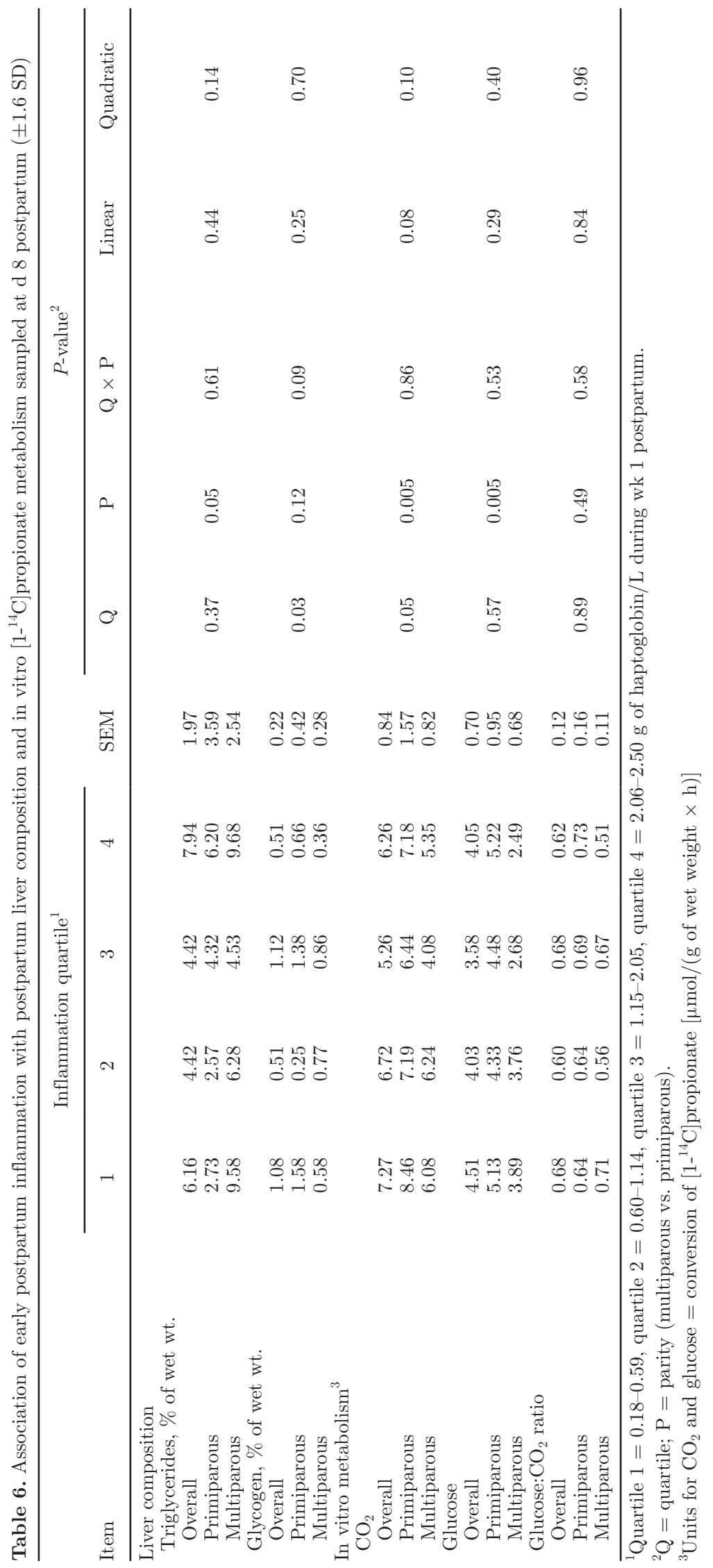


INFLAMMATION IN THE POSTPARTUM COW

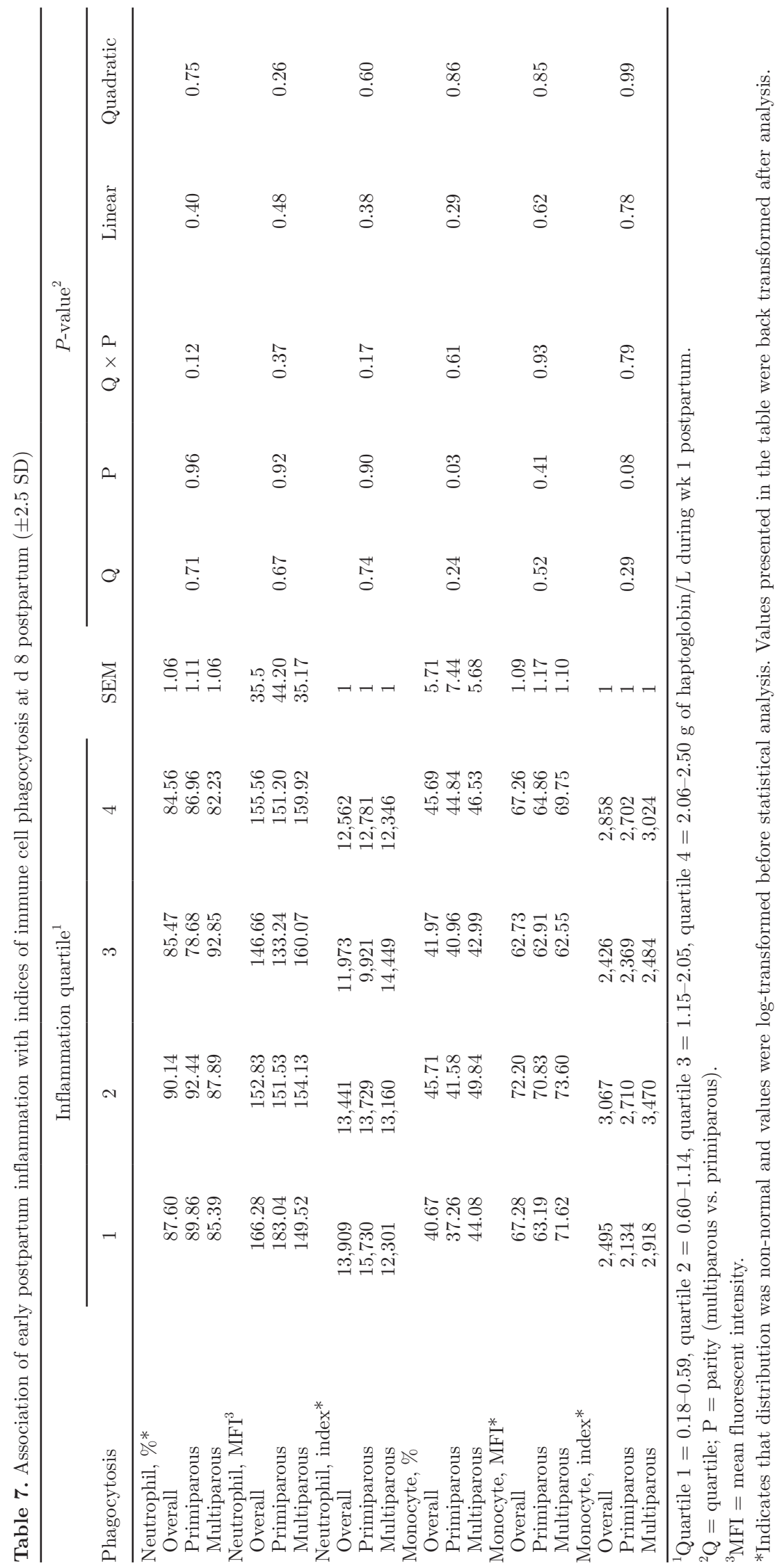




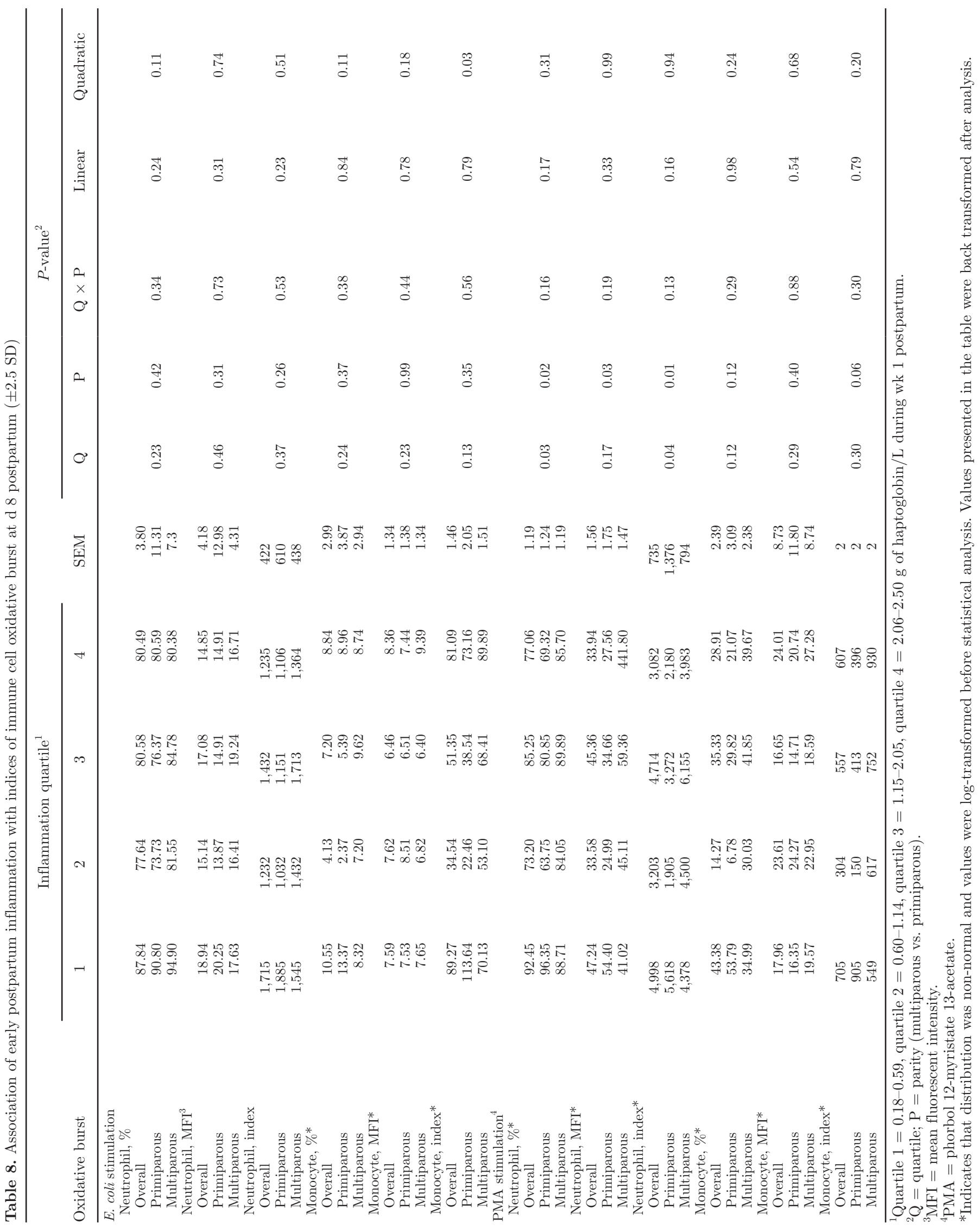


be hypophagic (Klasing, 1988); however, the alterations in DMI and BW for cows with lower-grade early lactation inflammation requires further investigation.

In human patients who had suffered major trauma, it was reported that resting energy expenditure increased to $40 \%$ above normal and continued to be elevated 3 wk after the onset of trauma (Plank and Hill, 2000). In the context of the current study, this would perhaps indicate that cows in Q2 and Q3 that had lower DMI and greater BW loss had less available energy to mount a sufficient immune response to the inflammatory event and experienced a state of prolonged immunosuppression because of the lack of sufficient energy.

Bertoni et al. (2008) also observed that cows with a low liver activity index in early lactation (indicating a greater degree of inflammation) had a $6.5 \mathrm{~kg} / \mathrm{d}$ reduction in milk yield compared with cows with very little early lactation inflammation, and numerical reductions in milk yield with each increase in inflammatory quartile. However, in the current study, reductions in milk were not linear, as cows in Q2 and Q3 tended to have the lowest $3.5 \%$ FCM and ECM yields.

In the current study, the metabolic response to inflammation as indicated by plasma metabolites was similar between Q3 and Q4 cows. Cows in Q3 and Q4 had elevated early lactation plasma glucose and insulin, perhaps indicating increased insulin resistance, as insulin resistance has been implicated in the inflammatory response (LeBlanc, 2012). Although TNF- $\alpha$ administration in early postpartum cows did not alter postpartum plasma metabolite response (Yuan et al., 2013), salicylate treatment during the immediate postpartum period altered the metabolic adaptations to lactation after salicylate treatment ended on d 7, leading to increases in BHB and NEFA, indicating that inflammation-associated pathways are involved in the adaptations to lactation (Farney et al., 2013). In contrast to results of the current study, Trevisi et al. (2012) observed that cows with a low liver activity index (indicative of a greater degree of inflammation) had lower glucose at calving and elevated postpartum NEFA and BHB compared with cows with a high liver activity index. Energy for phagocytosis of neutrophils is mostly dependent on intercellular glycogen (Naidu and Newbould, 1973) and glucose is one of the main oxidative fuels for macrophages (Newsholme et al., 1987). In the current study, we observed the greatest relationships of early lactation inflammation on impairments in neutrophil and monocyte oxidative burst ability. Because of the decreases in DMI for cows in Q2 and Q3, it is likely that cows in Q2 and Q3 also had less energy available for immune cell functionality. Insulin modulates immune cell response (Helderman, 1981) and may also have a direct effect on metabolism

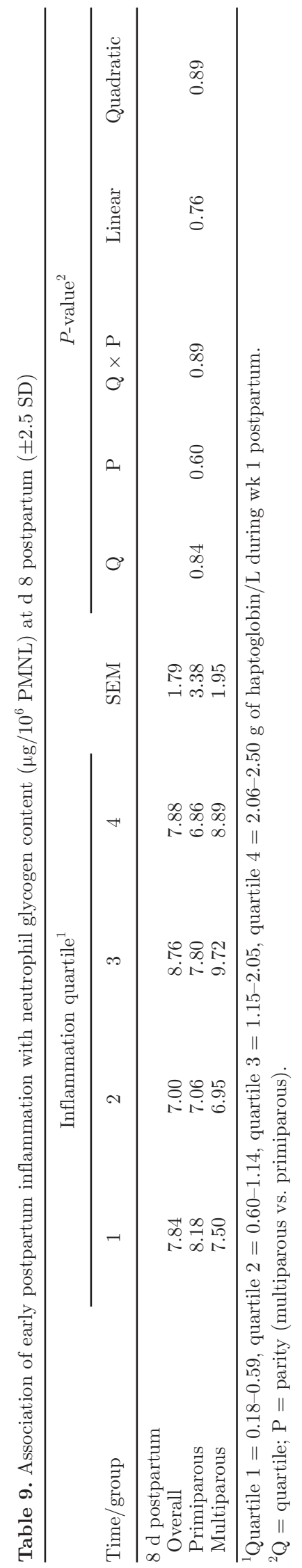

Journal of Dairy Science Vol. 99 No. 1, 2016 
and function in neutrophils (Alba-Loureiro, 2006), although we did not observe any effects of inflammation on neutrophil glycogen content at d 8 postpartum in the current study. During the early postpartum period, it appears that cows in Q3 and Q4 had higher plasma glucose compared with cows in Q1 and Q2, with a similar pattern for higher plasma insulin concentrations in cows in Q3 and Q4. Cows in Q2 had the lowest plasma glucose concentrations, and this reduction was likely driven by a $\mathrm{Q} \times$ parity interaction such that primiparous cows in Q2 had the greatest reductions in plasma glucose. However, there were only 3 primiparous cows Q2 and caution must be taken when interpreting results from the $\mathrm{Q} \times$ parity interactions. Macrophages and neutrophils have been shown to express glucose transporter (GLUT)1, GLUT3, and GLUT4 isoforms on the plasma membrane of both resting and activated cells (Maratou et al., 2007), and insulin stimulates both phagocytosis and the rate of glucose utilization (Newsholme et al., 1996). In vitro experiments utilizing activated macrophages and neutrophils incubated at increasing concentrations of insulin showed an increase in the GLUT4 MFI (Maratou et al., 2007). Glucose utilization rates in activated immune cells are high, and a large proportion of the glucose is metabolized to lactate in both macrophages (Newsholme et al., 1986) and neutrophils (Curi et al., 1997).

Cytokines IL-1 and TNF- $\alpha$ have been shown to increase gluconeogenesis and glucose oxidation (Klasing, 1988). In the current study, we found no difference between quartiles in utilization of $\left[1-{ }^{14} \mathrm{C}\right]$ propionate for in vitro liver slice conversion to glucose at $\mathrm{d} 7$ postpartum. However, we did observe an effect of quartile on conversion to $\mathrm{CO}_{2}$ and a quadratic tendency suggests decreased conversion of $\left[1-{ }^{14} \mathrm{C}\right]$ propionate to $\mathrm{CO}_{2}$ in cows in Q2 and Q3. Karnovsky et al. (1975) observed a 4 -fold increase in conversion of $\left[6-{ }^{14} \mathrm{C}\right]$ glucose to ${ }^{14} \mathrm{CO}_{2}$ during phagocytosis in activated macrophages compared with resting murine cells. In vitro leukocyte activation index is positively correlated with glucose status in blood from periparturient dairy cows (Schwarm et al., 2013), which indicates that innate immune activation is modulated by energy availability. The decreased conversion of $\left[1-{ }^{14} \mathrm{C}\right]$ propionate to $\mathrm{CO}_{2}$ in the current study along with decreased DMI would also suggest that there may be a decreased energy availability.

Because $\mathrm{Hp}$ is a nonspecific marker of inflammation, we are not able to speculate on the cause of the early lactation elevation in Hp for cows in Q2, Q3, and Q4 in the current study. Although cows in Q2, Q3, and Q4 all mounted some degree of inflammatory response during the early postpartum period, it is likely that Q4 cows were able to mount a more sufficient antiinflammatory response to eliminate the pathogen insult, whereas Q2 and Q3 cows were not able to mount a sufficient response, resulting in performance losses for those cows. The decrease in prepartum DMI for cows in Q2 and the postpartum decrease in DMI for cows in Q2 and Q3 indicated that perhaps this decrease in energy intake impaired their ability to mount a sufficient immune response during the immediate postpartum period, leading to postpartum impairments in immune function and sustained decreased productive performance.

Fatty liver has been reported to induce production of Hp (Murata et al., 2004; Guzelbektes et al., 2010), although it has also been suggested that fatty liver may suppress the secretion of acute phase proteins (Ingvartsen et al., 2003). Cytokine TNF- $\alpha$ has been shown to increase hepatic triglyceride synthesis (Klasing, 1988), although cytokines were not measured in the current study. Interestingly, at d 7 postpartum, cows in Q4 had high triglyceride content, whereas quadratic tendencies suggested that Q2 and Q3 cows had the lowest triglyceride content, again indicating differences in response to early lactation inflammation.

\section{CONCLUSIONS}

Although Q3 cows had alterations in energy metabolism similar to those of Q4 cows (as indicated by plasma metabolites), cows in Q2 and Q3 exhibited the most negative detriments in early lactation performance, as indicated by decreased DMI and greater sustained BW loss through wk 9 of lactation compared with cows in Q1 and Q4. These data suggest that insufficient energy availability impairs the ability of the animal to mount a sufficient immune response. More in-depth investigations of early lactation inflammation and the mechanistic response and role of immune function are necessary to better understand the different adaptation strategies of individual cows to inflammation in early lactation. Overall, cows with any degree of elevated haptoglobin in the first week after calving had alterations in both pre- and postpartum intake and postpartum metabolism, and cows that fell within the established high Hp cut-points $(>1.1 \mathrm{~g} / \mathrm{L})$ in this study had a diverse range of production responses. This suggests that these cut-points may not be specific enough to be useful as a management tool in their present state, and further investigation is warranted.

\section{ACKNOWLEDGMENTS}

The authors sincerely appreciate and gratefully acknowledge the assistance of G. Birdsall and the staff at the Cornell University Dairy Teaching and Research Center (Harford, NY) for their care of the cows on this study, as well as the as assistance of C. M. Ryan and 
S. H. Pelton and the undergraduate research assistance of E. Martens, R. Foley, K. Brust, and A. Forstater (all of Cornell University, Ithaca, NY). We also thank F. Vermeylen for her time with consultation on the statistical analyses and B. M. Sweeney (both of Cornell University) for her discussions on interpretation of immune function data. The parent study was funded in part by Elanco Animal Health (Greenfield, IN).

\section{REFERENCES}

Alba-Loureiro, T. C. 2006. Diabetes causes marked changes in function and metabolism of rat neutrophils. J. Endocrinol. 188:295-303.

Bernal-Santos, G., J. W. Perfield II, D. M. Barbano, D. E. Bauman, and T. R. Overton. 2003. Production responses of dairy cows to dietary supplementation with conjugated linoleic acid (CLA) during the transition period and early lactation. J. Dairy Sci. 86:32183228 .

Bertoni, G., E. Trevisi, X. Han, and M. Bionaz. 2008. Effects of inflammatory conditions on liver activity in puerperium period and consequences for performance in dairy cows. J. Dairy Sci. 91:33003310 .

Bionaz, M., E. Trevisi, L. Calamari, F. Librandi, A. Ferrari, and G. Bertoni. 2007. Plasma paraoxonase, health, inflammatory conditions, and liver function in transition dairy cows. J. Dairy Sci. 90:1740-1750.

Bradford, B. J., L. K. Mamedova, J. E. Minton, J. S. Drouillard, and B. J. Johnson. 2009. Daily injection of tumor necrosis factor- $\alpha$ increases hepatic triglycerides and alters transcript abundance of metabolic genes in lactating dairy cattle. J. Nutr. 139:1451-1456.

Burvenich, C., V. Van Merris, J. Mehrzad, A. Diez-Fraile, and L. Duchateau. 2003. Severity of E. coli mastitis is mainly determined by cow factors. Vet. Res. 34:521-564.

Canning, B. J., R. R. Hmieleski, E. W. Spannhake, and G. J. Jakab. 1991. Ozone reduces murine alveolar and peritoneal macrophage phagocytosis: The role of prostanoids. Am. J. Physiol. 261:L277L282.

Curi, T. C., M. P. De Melo, R. B. De Azevedo, T. M. Zorn, and R. Curi. 1997. Glutamine utilization by rat neutrophils: presence of phosphate-dependent glutaminase. Am. J. Physiol. 273:C1124C1129.

Farney, J. K., L. K. Mamedova, J. F. Coetzee, B. KuKanich, L. M. Sordillo, S. K. Stoakes, J. E. Minton, L. C. Hollis, and B. J. Bradford. 2013. Anti-inflammatory salicylate treatment alters the metabolic adaptations to lactation in dairy cattle. Am. J. Physiol. Regul. Integr. Comp. Physiol. 305:R110-R117.

Flaminio, M. J. B. F., B. R. Rush, E. G. Davis, K. Hennessy, W. Shuman, and M. J. Wilkerson. 2002. Simultaneous flow cytometric analysis of phagocytosis and oxidative burst activity in equine leukocytes. Vet. Res. Commun. 26:85-92.

Fletcher, M. J. 1968. A colorimetric method for estimating serum triglycerides. Clin. Chim. Acta 22:393-397.

Folch, J., M. Lees, and G. H. Sloane-Stanley. 1957. A simple method for the isolation and purification of total lipids from animal tissues. J. Biol. Chem. 226:497-509.

Foster, L. B., and R. T. Dunn. 1973. Stable reagents for determination of serum triglycerides by a colorimetric Hantzsch condensation method. Clin. Chem. 19:338-340.

Galvão, K. N., M. J. B. F. Flaminio, S. B. Brittin, R. Sper, M. Fraga, L. Caixeta, A. Ricci, C. L. Guard, W. R. Butler, and R. O. Gilbert. 2010. Association between uterine disease and indicators of neutrophil and systemic energy status in lactating Holstein cows. J. Dairy Sci. 93:2926-2937.

Guzelbektes, H., I. Sen, M. Ok, P. D. Constable, M. Boydak, and A. Coskun. 2010. Serum amyloid A and haptoglobin concentrations and liver fat percentage in lactating dairy cows with abomasal displacement. J. Vet. Intern. Med. 24:213-219.
Hammon, D. S., I. M. Evjen, T. R. Dhiman, J. P. Goff, and J. L. Walters. 2006. Neutrophil function and energy status in Holstein cows with uterine health disorders. Vet. Immunol. Immunopathol. 113:21-29.

Helderman, J. H. 1981. Role of insulin in the intermediary metabolism of the activated thymic-derived lymphocyte. J. Clin. Invest. 67:1636-1642.

Huzzey, J. M., T. F. Duffield, S. J. LeBlanc, D. M. Veira, D. M. Weary, and M. A. G. von Keyserlingk. 2009. Short communication: Haptoglobin as an early indicator of metritis. J. Dairy Sci. 92:621-625.

Huzzey, J. M., D. V. Nydam, R. J. Grant, and T. R. Overton. 2011. Associations of prepartum plasma cortisol, haptoglobin, fecal cortisol metabolites, and nonesterified fatty acids with postpartum health status in Holstein dairy cows. J. Dairy Sci. 94:5878-5889.

Huzzey, J. M., D. V. Nydam, R. J. Grant, and T. R. Overton. 2012. Association of biomarkers of stress, inflammation, and negative energy balance with milk yield and reproductive performance in Holstein dairy cows. J. Dairy Sci. 95(E. Suppl. 1):705. (Abstr.)

Ingvartsen, K. L., R. J. Dewhurst, and N. C. Friggens. 2003. On the relationship between lactational performance and health: Is it yield or metabolic imbalance that cause production diseases in dairy cattle? A position paper. Livest. Prod. Sci. 83:277-308.

Karnovsky, M. L., J. Lazdins, D. Drath, and A. Harper. 1975. Biochemical characteristics of activated macrophages. Ann. N. Y. Acad. Sci. 256:266-274.

Kettelhut, I. C., W. Fiers, and A. L. Goldberg. 1987. The toxic effects of tumor necrosis factor in vivo and their prevention by cyclooxygenase inhibitors. Proc. Natl. Acad. Sci. USA 84:4273-4277.

Klasing, K. C. 1988. Nutritional aspects of leukocytic cytokines. J. Nutr. 118:1436-1446.

Knapp, J. R., H. C. Freetly, B. L. Reis, C. C. Calvert, and R. L. Baldwin. 1992. Effects of somatotropin and substrates on patterns of liver metabolism in lactating dairy cattle. J. Dairy Sci. 75:1025-1035.

LeBlanc, S. J. 2012. Interactions of metabolism, inflammation, and reproductive tract health in the postpartum period in dairy cattle. Reprod. Domest. Anim. 47:18-30.

Maratou, E., G. Dimitriadis, A. Kollias, E. Boutati, V. Lambadiari, P. Mitrou, and S. A. Raptis. 2007. Glucose transporter expression on the plasma membrane of resting and activated white blood cells. Eur. J. Clin. Invest. 37:282-290.

McCarthy, M. M., T. Yasui, C. M. Ryan, G. D. Mechor, and T. R. Overton. 2015a. Performance of early-lactation dairy cows as affected by dietary starch and monensin supplementation. J. Dairy Sci. 98:3335-3350.

McCarthy, M. M., T. Yasui, C. M. Ryan, S. H. Pelton, G. D. Mechor, and T. R. Overton. 2015b. Metabolism of early-lactation dairy cows as affected by dietary starch and monensin supplementation. J. Dairy Sci. 98:3351-3365.

Moya, S. L., M. A. Gomez, L. A. Boyle, J. F. Mee, B. O'Brien, and S. Arkins. 2008. Effects of milking frequency on phagocytosis and oxidative burst activity of phagocytes from primiparous and multiparous dairy cows during early lactation. J. Dairy Sci. 91:587-595.

Murata, H., N. Shimada, and M. Yoshioka. 2004. Current research on acute phase proteins in veterinary diagnosis: An overview. Vet. J. 168:28-40.

Nachiappan, V., D. Curtiss, B. E. Corkey, and L. Kilpatrick. 1994. Cytokines inhibit fatty acid oxidation in isolated rat hepatocytes: synergy among TNF, IL-6, and IL-1. Shock 1:123-129.

Naidu, T. G., and F. H. Newbould. 1973. Glycogen in leukocytes from bovine blood and milk. Can. J. Comp. Med. 37:47-55.

Newsholme, P., R. Curi, S. Gordon, and E. A. Newsholme. 1986. Metabolism of glucose, glutamine, long-chain fatty acids and ketone bodies by murine macrophages. Biochem. J. 239:121-125.

Newsholme, P., S. Gordon, and E. A. Newsholme. 1987. Rates of utilization and fates of glucose, glutamine, pyruvate, fatty acids and ketone bodies by mouse macrophages. Biochem. J. 242:631-636.

Newsholme, P., L. Rosa, E. A. Newsholme, and R. Curi. 1996. The importance of fuel metabolism to macrophage function. Cell Biochem. Funct. 14:1-10. 
NRC. 2001. Nutrient Requirements of Dairy Cattle. 7th rev. ed. Natl. Acad. Sci., Washington, DC.

Plank, L. D., and G. L. Hill. 2000. Sequential metabolic changes following induction of systemic inflammatory response in patients with severe sepsis or major blunt trauma. World J. Surg. 24:630-638.

Schwarm, A., T. Viergutz, B. Kuhla, H. M. Hammon, and M. Schweigel-Roentgen. 2013. Fuel feeds function: Energy balance and bovine peripheral blood mononuclear cell activation. Comp. Biochem. Physiol. A Mol. Integr. Physiol. 164:101-110.

Sordillo, L. M., G. M. Pighetti, and M. R. Davis. 1995. Enhanced production of bovine tumor necrosis factor-alpha during the periparturient period. Vet. Immunol. Immunopathol. 49:263-270.

Strang, B. D., S. J. Bertics, R. R. Grummer, and L. E. Armentano. 1998. Effect of long-chain fatty acids on triglyceride accumulation, gluconeogenesis, and ureagenesis in bovine hepatocytes. J. Dairy Sci. 81:728-739.

Trevisi, E., M. Amadori, A. M. Bakudila, and G. Bertoni. 2009. Metabolic changes in dairy cows induced by oral, low-dose interferon-alpha treatment. J. Anim. Sci. 87:3020-3029. http://dx.doi. org/10.2527/jas.2008-1178.
Trevisi, E., M. Amadori, S. Cogrossi, E. Razzuoli, and G. Bertoni 2012. Metabolic stress and inflammatory response in high-yielding, periparturient dairy cows. Res. Vet. Sci. 93:695-704.

Veenhuizen, J. J., J. K. Drackley, M. J. Richard, T. P. Sanderson, L. D. Miller, and J. W. Young. 1991. Metabolic changes in blood and liver during development and early treatment of experimental fatty liver and ketosis in cows. J. Dairy Sci. 74:4238-4253.

Wildman, E. E., G. M. Jones, P. E. Wagner, R. L. Boman, H. F. Troutt, and T. N. Lesch. 1982. A dairy cow body condition scoring system and its relationship to selected production characteristics. J. Dairy Sci. 65:495-501.

Yasui, T., K. McCann, R. O. Gilbert, D. V. Nydam, and T. R. Overton. 2014. Associations of cytological endometritis with energy metabolism and inflammation during the periparturient period and early lactation in dairy cows. J. Dairy Sci. 97:2763-2770.

Yuan, K., J. K. Farney, L. K. Mamedova, L. M. Sordillo, and B. J. Bradford. 2013. TNFalpha altered inflammatory responses, impaired health and productivity, but did not affect glucose or lipid metabolism in early-lactation dairy cows. PLoS ONE 8:e80316. 